\title{
Disruption of TBP-2 ameliorates insulin sensitivity and secretion without affecting obesity
}

Eiji Yoshihara ${ }^{1,2}$, Shimpei Fujimoto ${ }^{3}$, Nobuya Inagaki ${ }^{3}$, Katsuya Okawa ${ }^{4}$, So Masaki', Junji Yodoi ${ }^{1}$ \& Hiroshi Masutani ${ }^{1}$

Type 2 diabetes mellitus (T2DM) is characterized by defects in both insulin sensitivity and glucose-stimulated insulin secretion (GSIS) and is often accompanied by obesity. In this study, we show that disruption of thioredoxin binding protein-2 (TBP-2, also called Txnip) in obese mice (ob/ob) dramatically improves hyperglycaemia and glucose intolerance, without affecting obesity or adipocytokine concentrations. TBP-2-deficient ob/ob mice exhibited enhanced insulin sensitivity with activated insulin receptor substrate-1/Akt signalling in skeletal muscle and GSIS in islets compared with ob/ob mice. The elevation of uncoupling protein-2 (UCP2) expression in ob/ob islets was downregulated by TBP-2 deficiency. TBP-2 overexpression suppressed glucose-induced adenosine triphosphate production, $\mathrm{Ca}^{2+}$ influx and GSIS. In $\beta$ cells, TBP-2 enhanced the expression level and transcriptional activity of UCP-2 by recruitment of peroxisome proliferator-activated receptor- $\gamma$ co-activator- $1 \alpha$ to the UCP-2 promoter. Thus, TBP-2 is a key regulatory molecule of both insulin sensitivity and GSIS in diabetes, raising the possibility that inhibition of TBP-2 may be a novel therapeutic approach for T2DM.

\footnotetext{
${ }^{1}$ Department of Biological Responses, Institute for Virus Research, Kyoto University, Kyoto 606-8507, Japan. ${ }^{2}$ Division of Systemic Life Science, Graduate School of Biostudies, Kyoto University, Kyoto 606-8501, Japan. ${ }^{3}$ Department of Diabetes and Clinical Nutrition, Faculty of Medicine, Kyoto University, Kyoto 606-8507, Japan. ${ }^{4}$ Drug Discovery Research Laboratories, Kyowa Hakko Kirin Co. Ltd, Shizuoka 411-8731, Japan. Correspondence and requests for materials should be addressed to H.M. (email: hmasutan@virus.kyoto-u.ac.jp).
} 
$\mathrm{R}$ egulation of glucose homeostasis is critical to life in mammals and is largely maintained by pancreatic $\beta$-cells, which secrete insulin in response to increased concentrations of glucose, and is also maintained by the glucose uptake response to insulin in peripheral tissues. Obesity disrupts glucose homeostasis and leads to diseases such as type 2 diabetes (T2DM), which is characterized by aggravated insulin sensitivity and insulin secretion ${ }^{1-5}$.

Thioredoxin binding protein-2 (TBP-2), also known as thioredoxin interacting protein (Txnip) ${ }^{6}$ and vitamin-D3 upregulated protein-1 $(\mathrm{VDUP} 1)^{7}$, has been identified as a negative regulator of thioredoxin and is mainly localized in the nucleus ${ }^{8,9}$. TBP-2 is a member of the $\alpha$-arrestin protein family, and contains two characteristic arrestinlike domains and two PPxY sequences, which is a known binding motif for WW domain containing proteins ${ }^{10-12}$. Evidence is growing that TBP-2 has an important role in a wide variety of biological functions, such as the regulation of cell death, cell growth, cell differentiation, immune responses and energy metabolism ${ }^{13-22}$. As our group and others have shown that TBP-2-deficient mice or mice carrying the TBP-2 nonsense mutation (HcB-19) have increased insulin sensitivity ${ }^{16,20,23}$ and insulin secretion ${ }^{16,18}$, we hypothesized that TBP-2 is involved in defects of insulin sensitivity and secretion in diabetes.

In this study, to address the physiological and molecular role of TBP-2 in diabetes, we generated a TBP-2-deficient diabetic mice model (ob/ob-TBP-2-/-). Remarkably, these mice displayed improved glucose intolerance due to enhanced muscle insulin sensitivity associated with the insulin receptor substrate-1 (IRS-1)/Akt pathway and glucose-stimulated insulin secretion (GSIS) in spite of obesity. The augmented insulin secretion was due to the elevation of glucoseinduced adenosine triphosphate (ATP) production with suppression of mitochondrial uncoupling protein-2 (UCP-2) expression. UCP-2 is known as a negative regulator of GSIS in diabetes ${ }^{24}$. We showed that TBP-2 regulates insulin secretion mainly through UCP-2 transcriptional activation in $\beta$-cell lines. We further investigated mechanisms for TBP-2 regulation of UCP-2 transcription and analysed interacting proteins for TBP- 2 in $\beta$-cells. The current results provide a novel mechanism for elucidating the pathogenesis of diabetes.

\section{Results}

Disruption of TBP-2 in ob/ob mice improves hyperglycaemia. Subsequent to a report that TBP-2 expression is elevated in skeletal muscle of patients with impaired glucose tolerance or $\mathrm{T}_{2} \mathrm{DM}^{19}$, we examined the expression levels of TBP-2 mRNA in the tissues of leptin-deficient (ob/ob) mice; a genetic animal model of human obesity and T2DM. Expression levels of TBP-2 were increased in the heart, skeletal muscle, white adipose tissue, kidney and pancreatic islets, but were not significantly changed in the liver of ob/ob mice compared with wild-type (WT) lean mice (Fig. 1a). To determine how TBP-2 is involved in the development of diabetic phenotypes in obese mice, we next studied the effect of endogenous TBP- 2 in ob/ob mice by generating TBP-2-deficient ob/ob mice (ob/ob.TBP-2 - / - ) (Fig. 1b). Ob/ob-TBP-2-/- mice did not show any significant change in food intake, but showed reduced water intake compared with that of ob/ob mice (Fig. 1c,d). Surprisingly, although body weight was higher in male and as high in female ob/ob.TBP-2-/ mice compared with that in ob/ob mice (Fig. 1e,g), TBP-2 deficiency markedly improved hyperglycaemia and urinary glucose excretion both in male and female ob/ob mice (Fig. 1f,h,i). Furthermore, glucose tolerance tests revealed significant amelioration of glucose metabolism in ob/ob.TBP-2-/ - mice (Fig. 1j,k), consistent with insulin tolerance tests (ITTs) in which insulin sensitivity significantly increased in ob/ob.TBP-2-/- mice compared with that in ob/ob mice (Fig. 1l,m). These results suggest that disruption of TBP-2 in $\mathrm{ob} / \mathrm{ob}$ mice improves glucose tolerance and insulin sensitivity.

TBP-2 deficiency ameliorates insulin resistance. As altered production of adipocytokines accompanied with obesity is implicated in insulin resistance and glucose intolerance ${ }^{2,25}$, body fat composition, serum monocyte chemotactic protein-1 (MCP-1), adiponectin and metabolic parameters of ob/ob.TBP-2 - / - mice were measured. In ob/ob.TBP-2 - / - mice, body fat and serum levels of fatty acids, MCP-1 and lipids increased and serum adiponectin decreased compared with those in WT and/or ob/ob mice (Fig. 2a-i and Supplementary Table S1). TBP-2 deficiency in ob/ob mice did not improve adipose size, and TBP-2-/- mice showed increased adipose size compared with that in WT mice (Fig. 2j). These results show that TBP-2 deficiency improves insulin sensitivity without amelioration of overeating, obesity and adipocyte dysfunction.

As insulin resistance is derived from defects in insulin signalling in peripheral tissues, ${ }^{1}$ and insulin/Akt signalling regulates many of the metabolic actions of insulin ${ }^{1}$, we investigated phosphorylation of Akt in these mice. Akt phosphorylation levels in both basal- and insulin-stimulated states were upregulated in skeletal muscle, heart and liver of TBP-2-/ - mice compared with those in WT mice (Fig. $2 \mathrm{k}-\mathrm{p}$ ). In addition, TBP-2 deficiency enhanced Akt phosphorylation levels in response to insulin in mouse embryonic fibroblasts (MEFs) (Fig. 2q,r), suggesting that TBP-2 deficiency enhances insulin/Akt signalling. Although ob/ob mice showed suppression of Akt phosphorylation in response to insulin in skeletal muscle, heart and liver, compared with those in WT mice without affecting the concentration of total Akt protein, TBP-2 deficiency in $\mathrm{ob} / \mathrm{ob}$ mice restored the suppression of Akt phosphorylation in skeletal muscle and heart, but not liver (Fig. $2 \mathrm{k}-\mathrm{p}$ ). The phosphorylation of FoxO1, an Akt downstream signalling molecule, was also not enhanced in the liver of ob/ob.TBP-2 - / - mice. Severe lipid accumulation occurred in the liver both in ob/ob and ob/ob-TBP-2 - / mice (Supplementary Fig. S1a,b). Thus, the amelioration of insulin sensitivity by TBP-2 deficiency in ob/ob mice seems to be due to activation of insulin/Akt signalling in skeletal muscle.

TBP-2 deficiency enhances IRS-1 expression in skeletal muscle. We performed microarray analyses (data deposited in GEO, accession number GSE24851) of the skeletal muscle in WT, TBP-2 - / -, ob/ob, ob/ob·TBP-2 - / - mice to investigate how TBP-2 regulates Akt signalling and insulin sensitivity. We found that several insulin signalling-related genes, such as Igf1, Igf2bp2, Igfbp4, Irs-1(IRS-1), Pik3r1 and Pik3r5, were upregulated by TBP-2 deficiency both in WT and ob/ob background mice (Supplementary Table S2). The upregulation was confirmed by real-time reverse transcription (RT)-PCR analyses (Fig. 3a). IRS-1 gene expression was downregulated in skeletal muscle of ob/ob mice (Fig. 3a) or T2DM patients $^{26}$. We focused on IRS-1, as IRS-1 is one of the key molecules for insulin signalling and is an upstream molecule of Akt in skeletal muscle ${ }^{27}$. IRS-1 protein levels were downregulated in ob/ob mice, whereas IRS-1 protein levels and phosphorylation of Akt were upregulated by TBP-2 deficiency in skeletal muscle of WT and ob/ob background mice (Fig. 3b). Thus, TBP-2 regulates the expression of molecules involved in insulin signalling, which may enhance insulin sensitivity in skeletal muscle. Gene expressions of peroxisome proliferator-activated receptor (PPAR) signalling were also enhanced by TBP-2 deficiency in skeletal muscle (Supplementary Fig.S2).

TBP-2 deficiency improved impairment of insulin secretion. TBP-2-/ - mice and HcB-19 mice show enhanced insulin secretion in $v i v o^{16,18}$. Although obesity usually leads to insulin resistance, only a subset of obese- and insulin-resistant individuals progress to T2DM. In ob/ob mice and humans, the determinant factor for declining glucose tolerance is a progressive decrease in GSIS ${ }^{3}$. Of note, ob/ob mice showed elevated blood glucose with an increase in body weight after ages 5 or 6 weeks, whereas TBP-2-deficient ob/ob mice did not show elevation of blood glucose, in spite of similar increases in body weight. In addition, although blood glucose levels 
a

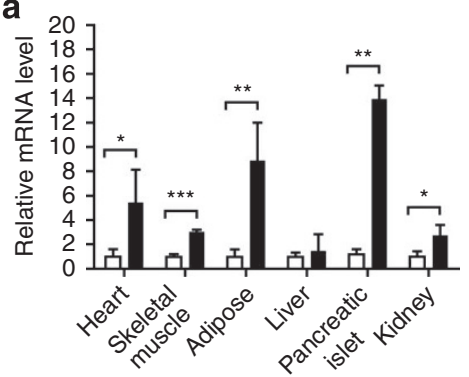

b

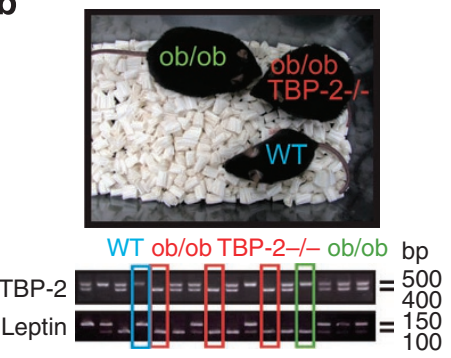

C

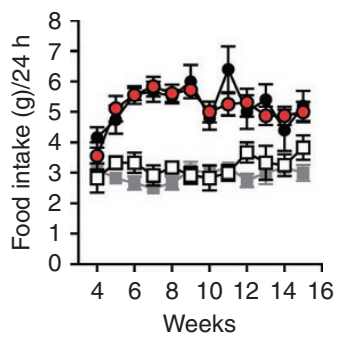

d

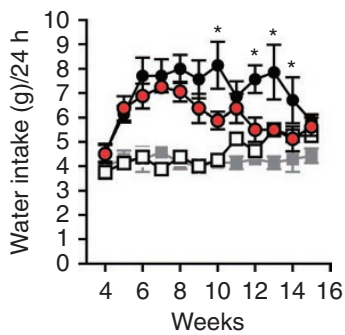

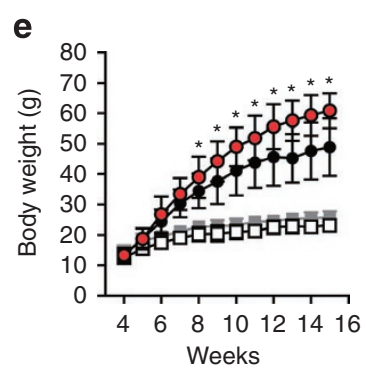

f

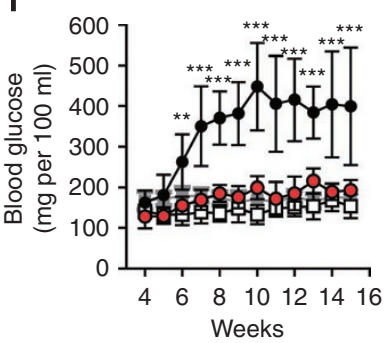

g

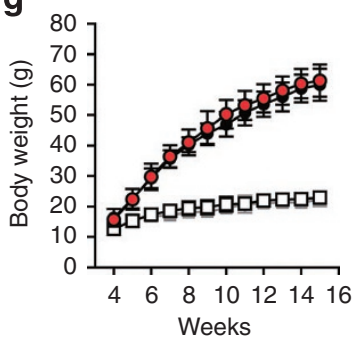

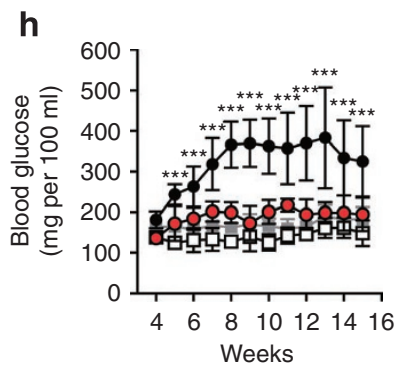

i

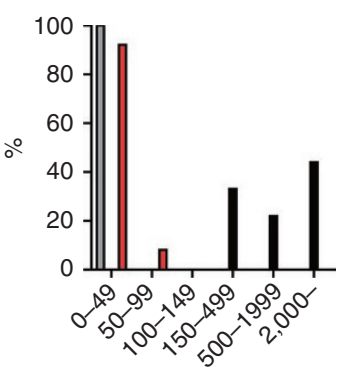

j

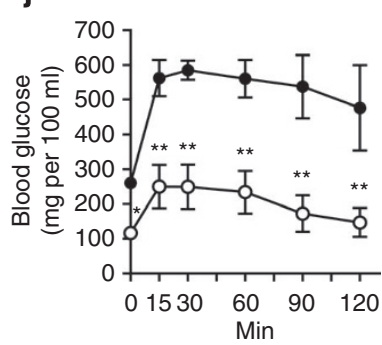

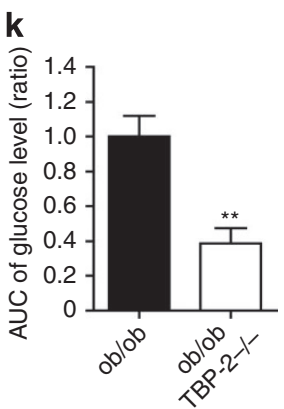

I
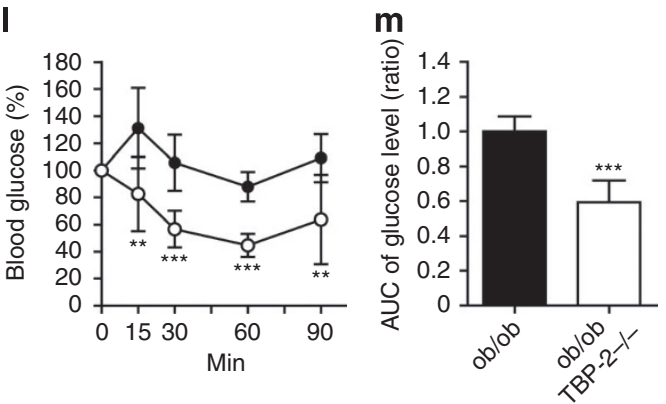

Urine glucose $(\mathrm{mg}$ per $100 \mathrm{ml})$

Figure 1 | Disruption of TBP-2 in ob/ob mice improves hyperglycaemia and glucose intolerance without affecting obesity. (a) Quantitative RT-PCR of TBP-2 expression in the heart, skeletal muscle, white adipose, liver, pancreatic islet and kidney of WT (open bar, lean, $n=3$ ) and ob/ob mice (closed bar, $n=3$ ). (b) Generation of the ob/ob·TBP-2 - / - mice. Male food intake (c), male water intake (d), male body weight (e), male blood glucose in fed ad lib (f),

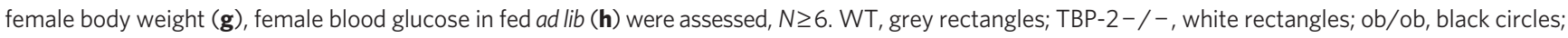
ob/ob·TBP-2 - / - , red circles. (i) Urine glucose (mg per $100 \mathrm{ml}$ ) of males and females. WT (grey bar; $n=11)$, ob/ob (black bar; $n=9$ ), ob/ob·TBP-2 - / (red bar; $n=11$ ). (j, k) Intraperitoneal glucose tolerance test (IPGTT). Following an overnight fast, mice were injected with $0.5 \mathrm{~g}$ kg ${ }^{-1}$ glucose, IP (time 0 ). Blood glucose values (j) and area under the curve (AUC) levels (k) were assessed before and at 15, 30, 60 and 120 min into the IPGTT. ob/ob (black circle, $n=5)$, ob/ob·TBP-2 - / - (white circle, $n=6)$. (I, m) IP insulin tolerance test (IPITT). Following a $6 \mathrm{~h}$ fast, mice were injected with $1 \mathrm{U} / \mathrm{kg}$ of insulin, i.p. (time 0). Blood glucose value (I) and AUC levels ( $\mathbf{m}$ ) were assessed before and at 15, 30, 60 and 90 min into the IPITT. ob/ob (black circle, $n=5$ ), ob/ob-TBP-2 - / - (white circle, $n=6)$. Data are presented as mean \pm s.d. ${ }^{\star} P<0.05,{ }^{\star \star} P<0.01,{ }^{\star \star \star} P<0.001$, versus control $(t$-test).

were lower in ob/ob·TBP-2 - / - mice, compared with those in ob/ob mice, serum insulin levels in ob/ob·TBP-2-/ - mice were as high as those in ob/ob mice at ages 11 and 14 weeks in both males and females (Fig. 4a,b). Although we observed no significant change in islet mass between ob/ob-TBP-2 - / - mice and ob/ob mice, as well as between TBP-2 - / - and WT mice (Fig. 4c,d), serum insulin levels after glucose loads in vivo were enhanced in ob/ob.TBP-2-1- mice compared with those in ob/ob mice (Fig. 4e). To evaluate the effect of TBP-2 deficiency on insulin secretion ex vivo, pancreatic islets were isolated from WT, TBP-2-/-, ob/ob and ob/ob.TBP-2-/- mice. TBP-2 deficiency enhanced GSIS in both WT and ob/ob mice (Fig. $4 \mathrm{f}, \mathrm{g})$. Insulin secretion from ob/ob islets in response to high glucose was blunted, and was improved by TBP-2 deficiency (Fig. 4g,h). These results suggest that TBP-2 deficiency improves impairment of GSIS from islets, which contributes to improvement of glucose intolerance in ob/ob mice. As glucose metabolism generates ATP as a signal to enhance insulin secretion ${ }^{28}$, we further determined ATP content of islets in these mice. Under a high $(16.7 \mathrm{mM})$ glucose condition, TBP2 deficiency enhanced ATP content in both WT and ob/ob islets (Fig. $4 \mathrm{i}, \mathrm{j})$. WT islets showed a significant increase in ATP production with increased glucose concentrations (Fig. 4i). In ob/ob islets, increases in ATP content with increasing glucose levels were not as marked (Fig. 4j,k), as in TBP-2 deficiency where the ratio of ATP content at high glucose $(16.7 \mathrm{mM})$ relative to basal glucose $(2.8 \mathrm{mM})$ was significantly increased (Fig. 4k). Regulation of mitochondrial ATP production has a central role in insulin secretion from pancreatic $\beta$ cells $^{4}$, and the reduction of mitochondrial ATP production parallels abnormal mitochondrial structure, including swelling and alteration in volume density and cristae structure ${ }^{29}$, which is often observed in diabetes ${ }^{5,30}$. We then studied the morphology of mitochondria in WT, TBP-2-/-, ob/ob and ob/ob-TBP-2-/ - $\beta$-cells using electron microscopy. Morphological apoptotic processes, including condensation of chromatin around the nuclear membrane and swelling of the cytoplasm and a decrease in the number of insulin granules in $\beta$-cells, were not observed in ob/ob and ob/ob-TBP-2-/- mice at 10 weeks ages (Supplementary Fig. S3a,b). However, the abnormal mitochondrial morphological changes, such as swelling associated with an increased number of disarrayed or disappeared cristae and a reduced electron density of the matrix, were observed in ob/ob mice, whereas the abnormalities were improved in ob/ob·TBP-2-/ - mice 

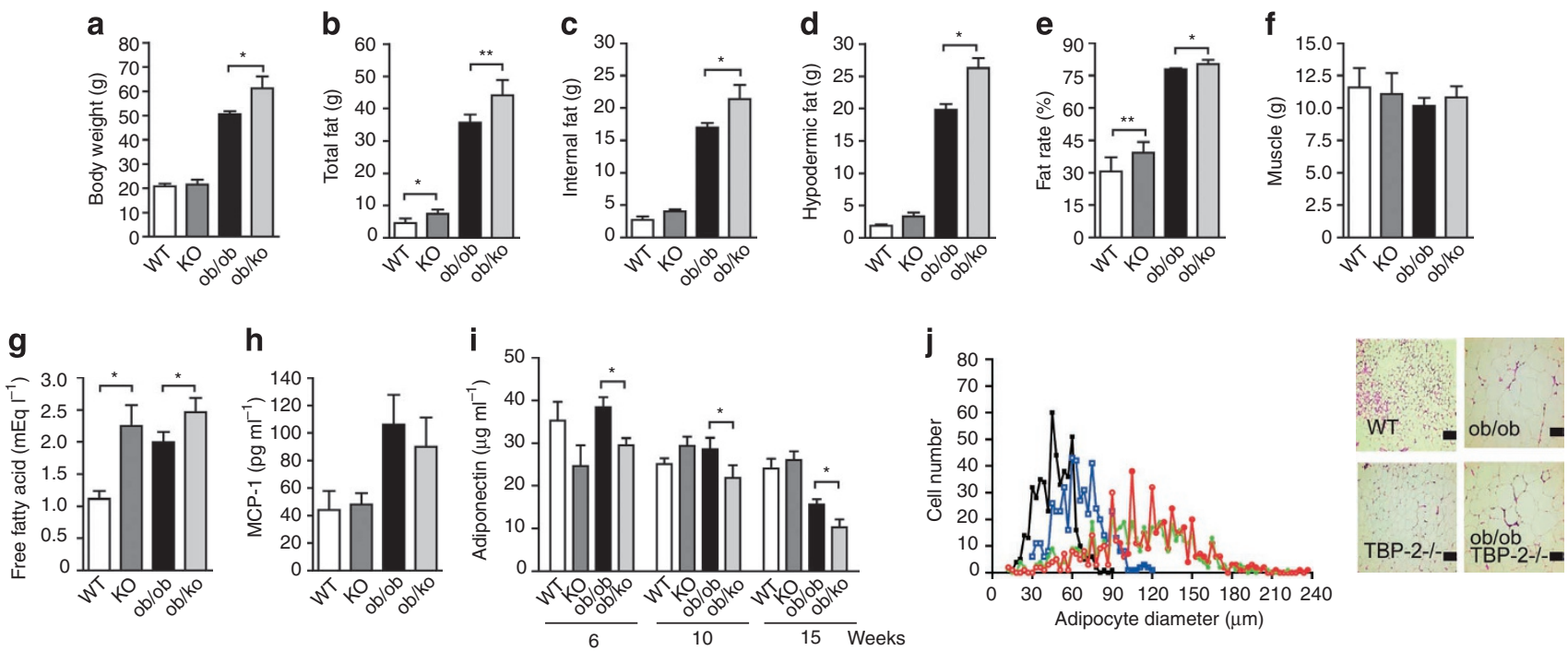

$\mathbf{k}$

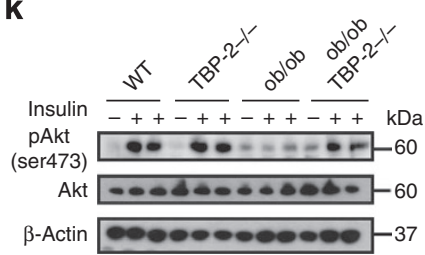

I
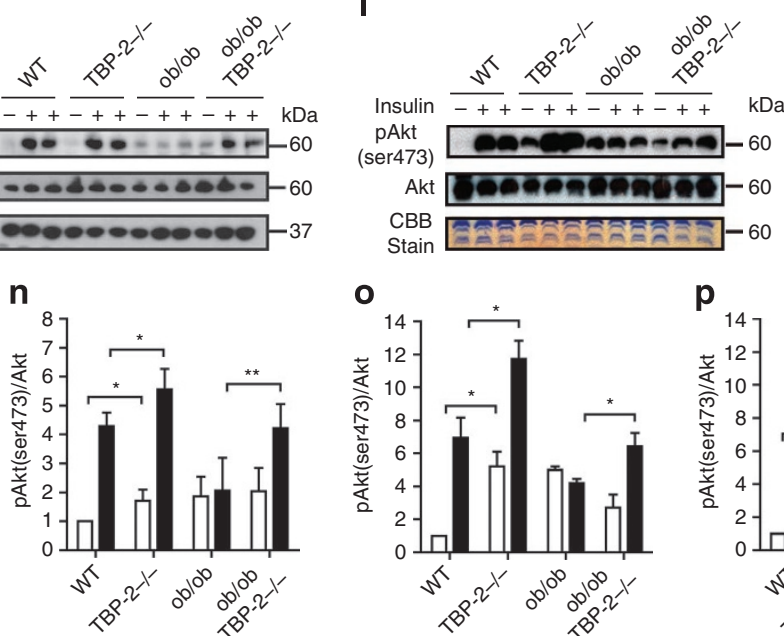

O

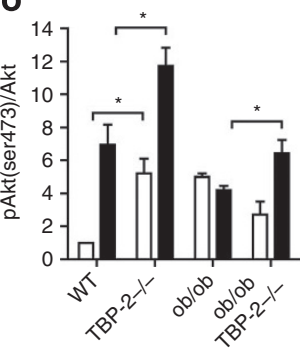

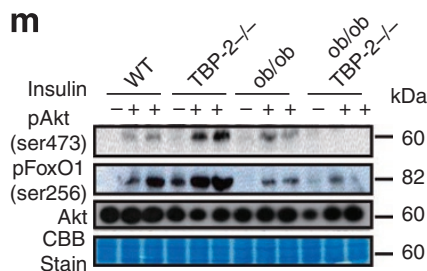

p

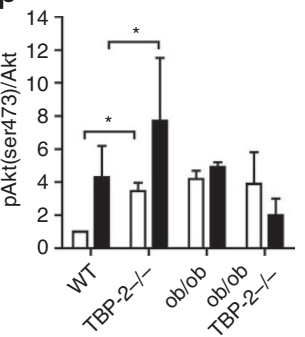

q

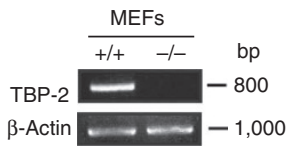

Figure 2 | TBP-2 deficiency ameliorates insulin resistance and increase Akt signalling. (a-f) Fat and muscle content. Body weight (a), total fat (b), internal fat (c), hypodermic fat (d), fat rate (e), muscle (f) in male WT (WT), TBP-2-/- (KO), ob/ob (ob/ob) and ob/ob-TBP-2-/ - (ob/ko) mice calculated from computed tomography scan data are shown for 15 weeks aged mice, $N \geq 4$. (g, h) Serum physiological parameters. Free fatty acid (g) and MCP-1 (h) were measured in 15 weeks aged mice, $N \geq 7$. (i) Blood adiponectin concentration was measured in 6,10 and 15 weeks aged mice, $n=\geq 5$. (j) Distribution of adipocyte size in white adipose from 10 weeks aged WT (black closed rectangle), TBP-2-/- (blue open rectangle), ob/ob (green closed circle) and ob/ob·TBP-2-/- (red open circle) mice (left panel). The right panel shows histological analyses of haematoxylin and eosin (HE)-stained white adipose sections in these mice. Scale bar indicates $100 \mu \mathrm{m}$. (k-m) Immuno blotting (IB) analyses of ser473-phospholylated Akt (pAkt), ser256phospholylated FoxO1 (pFoxO1) and total Akt in response to insulin $\left(2 \mathrm{U} \mathrm{kg}^{-1}\right)$ in skeletal muscle (k), heart (I) and liver (m). Densitometric quantification of pAkt/Akt ratios in skeletal muscle (n), heart (o) and liver (p). Open and closed bar represents without or with insulin stimulation, respectively. (q) Loss of endogenous TBP-2 mRNA in MEFs. ( $\mathbf{r}$ ) IB analyses. TBP-2 deficiency enhances insulin/Akt signalling in primary MEFs. MEFs were serum starved for $12 \mathrm{~h}$ and then stimulated with insulin $(100 \mathrm{nM})$ for different times. Data are presented as mean $\pm s . d .{ }^{\star} P<0.05,{ }^{\star \star} P<0.01$, versus control ( $t$-test).

(Fig. 4l). These results showed that mitochondrial morphological changes and metabolic dysfunctions in $\beta$-cells are improved by TBP2 deficiency in ob/ob mice.

TBP-2 suppresses mitochondrial ATP production and GSIS. To delineate how TBP-2 deficiency protects against the impaired GSIS in ob/ob islets, we next examined the dose effect of TBP-2 on GSIS in the rat $\beta$-cell line INS- 1 cells. Silencing of TBP-2 (RNAi1 and RNAi2) enhanced GSIS in INS-1 cells (Fig. 5a,b,d). On the contrary, transient TBP-2 overexpression suppressed GSIS (Fig. 5c,e). Induction of TBP-2 in cloned INS-1 cells, where TBP-2 expression was doxycycline-off dependent, suppressed GSIS, but not $\mathrm{KCl}$-induced insulin secretion (Fig. 5f,g). TBP-2 induction did not cause a significant change in ATP levels at low $(2.8 \mathrm{mM})$ glucose level, but it suppressed ATP levels at high $(16.7 \mathrm{mM})$ glucose in INS-1 cells (Fig. 5h). Furthermore, glucose-induced intracellular $\mathrm{Ca}^{2+}$ elevation, which is the eventual trigger for the exocytosis of insulin granules, was significantly decreased in TBP-2-induced INS-1 cells (Fig. 5i). We then analysed mitochondrial membrane potentials $\left(\Delta \psi_{\mathrm{m}}\right)$ in TBP-2induced INS- 1 cells. We showed that $\Delta \psi_{\mathrm{m}}$ was significantly reduced in TBP-2-induced INS-1 cells cultured with low $(3 \mathrm{mM})$ and high (20 mM) glucose (Fig. 5j) and with $11 \mathrm{mM}$ glucose for $24 \mathrm{~h}$ (Fig. 5k) using a flowcytometer and fluorescence microscopy, respectively. Cellular ATP is mainly produced by glycolysis and mitochondrial metabolism. In pancreatic $\beta$-cells, glycolytic flux regulates glucose metabolism, which has an important role in insulin secretion, and glucokinase is a pace-setting enzyme in glycolysis ${ }^{31}$. Therefore, effects of TBP-2 on glucokinase activity were examined. Glucokinase activity 
a
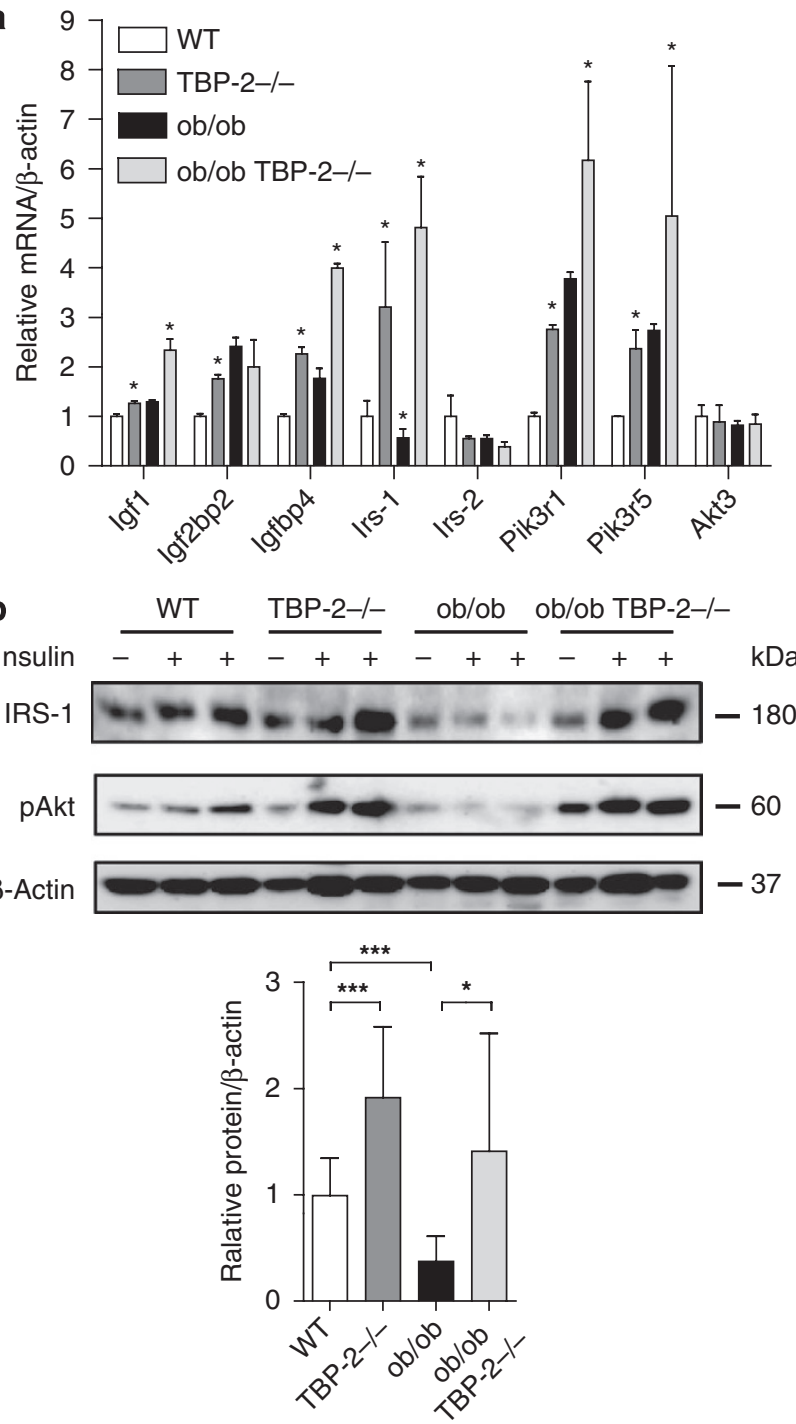

Figure 3 | Insulin signalling-related genes are upregulated by TBP-2 deficiency in skeletal muscle. The expression of insulin signal-related genes from the skeletal muscle of 10 weeks aged WT (white bar), TBP2-/- (dark grey bar), ob/ob (black bar) and ob/ob-TBP-2-/- (light grey bar) mice. (a) Real-time PCR analyses were performed. Asterisk indicates ${ }^{*} P<0.05 ; W T$ versus TBP- $2-/-$, WT versus ob/ob, ob/ob versus ob/ob-TBP-2 - / - . (b) Immuno blotting (IB) analyses, $n$ per group 3-5 each. Two $\mathrm{Ug}^{-1}$ insulin (+) or saline (-) was injected. Densitometric quantification of IRS-1/ $\beta$-actin is shown in the bar graph. Data are presented as mean \pm s.d. ${ }^{\star} P<0.05,{ }^{\star \star \star} P<0.001$, versus control ( $t$-test).

was not affected by dox-off-dependent TBP-2 induction in $\beta$-cells (Fig. 5l). Furthermore, effects of TBP-2 on insulin secretion stimulated by fuel secretagogues, which bypass glycolysis and are metabolized in mitochondria to generate ATP, were determined using methods previously described ${ }^{32}$. Insulin secretion induced by pyruvate and $\alpha$-ketoisocaprotate plus monomethyl succinate was also suppressed by TBP- 2 overexpression in $\beta$-cells (Fig. $5 \mathrm{~m}$ ). These results indicate that impaired GSIS by TBP-2 induction is attributable to reduction in mitochondrial metabolism, but not to a decrease in glycolysis.

TBP-2 has been reported to enhance apoptosis in pancreatic $\beta$-cells and other cells ${ }^{21}$. TBP-2 induction did not increase apoptosis in $48 \mathrm{~h}$, but apoptosis was slightly increased on $72 \mathrm{~h}$ after high $(20 \mathrm{mM})$ glucose treatment (Fig. $5 \mathrm{n}$ ). $\beta$-Cell apoptosis was not changed significantly between ob/ob and ob/ob TBP-2-/ - mice generated in a
C57BL/6J background at 10 weeks of age (Supplementary Figs S3a,b and S4a), whereas TBP-2 deficiency suppressed $\beta$-cell apoptosis at age 36 weeks in C57BL/6J background mice (Supplementary Fig. $\mathrm{S} 4 \mathrm{~b}, \mathrm{c})$. These results suggest that TBP- 2 negatively regulates GSIS by suppressing glucose-induced mitochondrial ATP production in INS1 cells and islets before causing apoptosis. Treatment with reactive oxygen species scavengers (vitamins $\mathrm{C}+\mathrm{E}$ ) scarcely recovered the insulin secretion suppressed by TBP-2 overexpression in INS-1 cells (Supplementary Fig. S5), suggesting that mitochondrial dysfunction caused by TBP-2 is not mainly attributed to an increase in reactive oxygen species by reducing the scavenger effect of thioredoxin.

TBP-2 enhances UCP-2 transcriptional activity. Impairment in mitochondria ATP production often occurs with uncoupling ${ }^{24}$. Mitochondrial UCP-2 is a key regulator of ATP production and insulin secretion in pancreatic $\beta$-cells, and UCP-2 deficiency has been shown to improve GSIS and glucose-induced ATP production in ob/ob mice ${ }^{24}$. Thus, we measured UCP-2 mRNA in TBP-2-overexpressed INS-1 cells. Strikingly, there was a significant increase in UCP-2 mRNA levels in the TBP-2-induced cells (Fig. 6a). Furthermore, TBP-2 induction also increased UCP-2 protein levels in the mitochondria of INS-1 cells (Fig. 6b). UCP-2 expression is known to be upregulated by the increase in activity of transcriptional co-activators; e.g., PPAR $\gamma$ co-activator- $1 \alpha(\mathrm{PGC}-1 \alpha)^{33}$. TBP-2 is also induced by PGC- $1 \alpha$ overexpression in INS-1 cells (Fig. $6 \mathrm{c}$ ). We examined the effect of TBP-2 overexpression on activity of UCP-2 -86 promoter, containing Sp1, SRE and double E-box elements, the essential elements for a response to fatty acids and PGC-1 $\alpha^{33,34}$. TBP- 2 enhanced UCP-2 transcriptional activity through this -86 promoter region and the PGC-1 $\alpha$-induced activation was also augmented by TBP-2 expression (Fig. 6d), suggesting that TBP-2 enhances UCP-2 transcriptional activity and expression in INS-1 cells. To investigate how TBP-2 regulates UCP-2 transcriptional activity, we tested whether TBP-2 affects PGC- $1 \alpha$ protein levels. Dox-off-dependent TBP-2 overexpression did not change PGC-1 $\alpha$ protein levels (Supplementary Fig. S6). Next, we used chromatin immunoprecipitations (ChIPs) to investigate whether TBP-2 expression influences PGC-1 $\alpha$ binding efficiency to the UCP-2 promoter region. Sheared chromatin was collected from INS-1 cells treated with or without doxycycline, and then immunoprecipitated with anti-RNA polymerase II or control-mouse immunoglobulin G or anti-PGC-1 $\alpha$ antibody. PCR was performed with primers flanking the SP1, SRE and E-boxes region of UCP-2 (UCP-2 -86). PGC-1 $\alpha$ was recruited to the UCP-2 -86 promoter region and dox-off-dependent TBP-2 overexpression enhanced PGC-1 $\alpha$ binding efficiency to the region (Fig. 6e,f). These results indicate that TBP- 2 facilitates PGC- $1 \alpha$ recruitment in the UCP-2 promoter region, enhancing UCP-2 transcriptional activity in INS-1 cells. Next, we tested whether TBP-2-dependent UCP-2 expression is critical for aggravated GSIS using UCP-2 knockdown in dox-off-dependent TBP-2-overexpressing INS-1 cells. UCP-2 knockdown reversed suppression of GSIS by TBP-2 induction (Fig. 6g and Supplementary Fig. S7), suggesting that TBP-2-induced suppression of GSIS is mainly through UCP-2 expression. Furthermore, the expression level of UCP-2 mRNA was enhanced in islets of ob/ob mice, whereas TBP-2 deficiency dramatically reduced it in ob/ob islets (Fig 6h). Mitochondrial mass, determined as mitochondrial coding gene (mtDNA)/nuclear coding gene (COX I) expression ratio in pancreatic islets, was not affected by TBP-2 deficiency (Fig. 6i). Next, we examined the effect of the mitochondrial uncoupler carbonyl cyanide m-chlorophenyl-hydrazone (cccp) on GSIS in Tet-TBP-2 INS-1 cells with or without doxycycline and in TBP-2 deficient ob/ob islets. Uncoupling by cccp decreased the GSIS at the concentration 25-1,000 nM (Supplementary Fig. S8a). This result suggests that mitochondria metabolism is responsible for GSIS in $\beta$-cells and is tightly regulated by uncoupling. In dox-off tet-TBP-2 INS-1 cells, TBP-2 overexpression suppressed the GSIS equivalent 
a

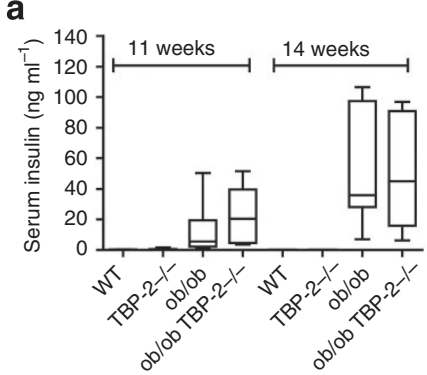

e

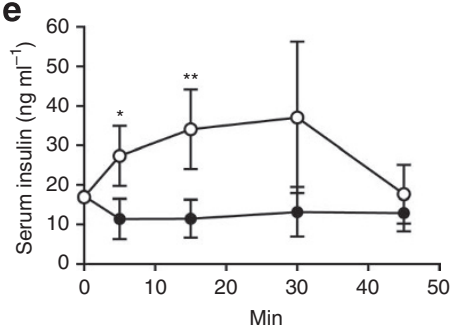

b

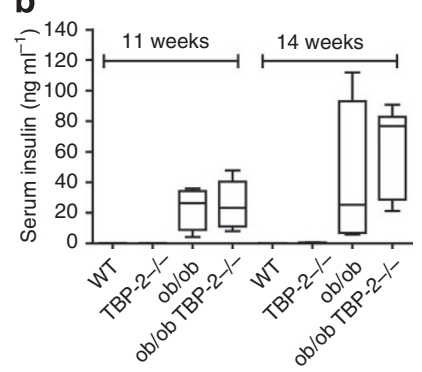

f

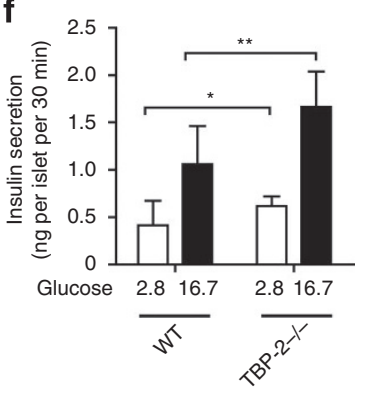

c

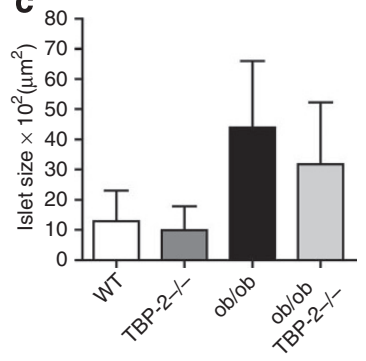

9

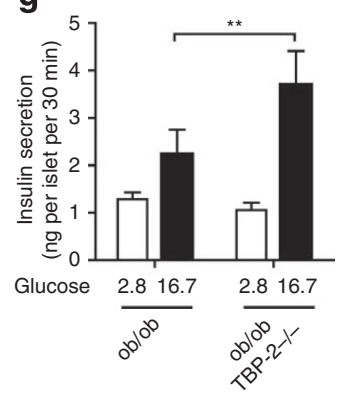

d

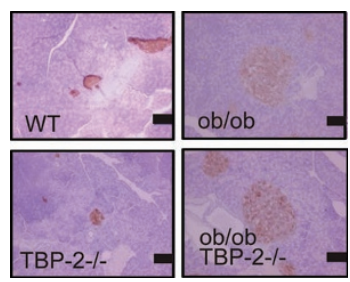

i

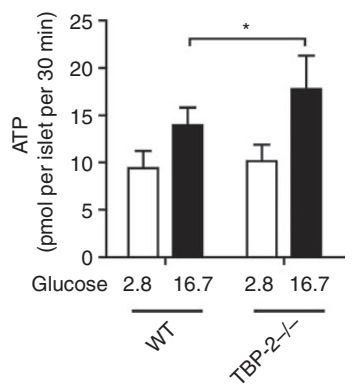

j

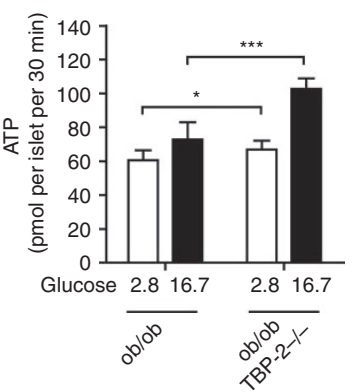

k

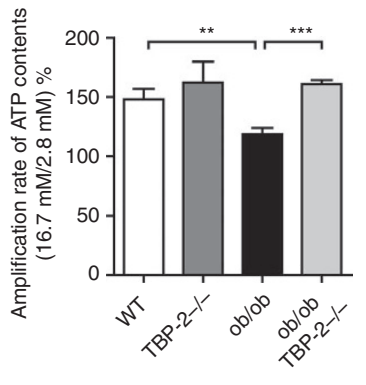

I

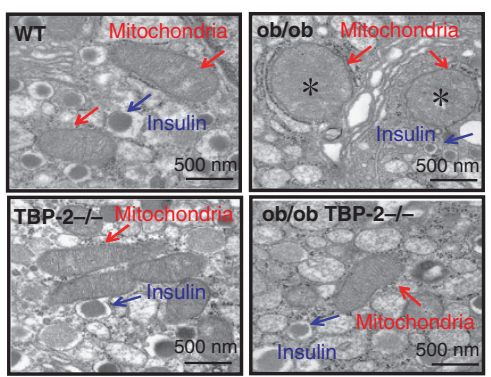

h

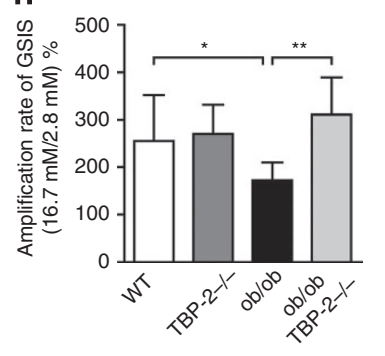

Figure 4 | Impairment of glucose-stimulated insulin secretion in ob/ob mice is improved by TBP-2 deficiency in vivo and ex vivo. Serum insulin concentrations at 11 and 14 weeks aged male (a) and female (b) mice. The median lines are shown in box graphs. $n=6-12$ per group. Physiological analyses of islet mass (c) and insulin immunostaining of islets (d) in 10 weeks aged mice. Scale bars, $100 \mu \mathrm{m} ; n=3$ per group. (e) Serum insulin levels during intraperitoneal glucose tolerance tests (IPGTTs). Following an overnight fast, mice were injected with $1 \mathrm{~g} \mathrm{~kg}^{-1} \mathrm{glucose}$, IP (time 0 ). Serum insulin values were assessed before and at 5, 15, 30 and 45 min into the IPGTT. ob/ob (closed circle, $n=6$ ), ob/ob-TBP-2- - - (open circle, $n=5$ ). (f-k) Batches of 10 pancreatic islets isolated from WT, TBP-2-/-, ob/ob and ob/ob·TBP-2-/- mice of 10 weeks age were stimulated with $2.8 \mathrm{mM}$ (open bar) or $16.7 \mathrm{mM}$ glucose (closed bar) for $30 \mathrm{~min}$. Insulin secretion ( $\mathbf{f}-\mathbf{h})$ and ATP contents (i-k) were measured by radioimmunoassay and a luminometer, respectively. WT was compared with TBP-2-/- (f, i) or ob/ob with ob/ob-TBP-2-/- $(\mathbf{g}, \mathbf{j})$. Amplification rate of insulin secretion (h) and ATP contents ( $\mathbf{k})$ at high (16.7 mM) glucose compared with basal $(2.8 \mathrm{mM})$ glucose stimulation for $30 \mathrm{~min}$. (I) Electron microscopic images of islet sections ( $\times 30200$; scale bar, $500 \mathrm{~nm})$. Magnified areas of individual $\beta$-cell mitochondria. Red arrows highlight individual mitochondria and blue arrows highlight insulin granules. * $S w e l l i n g$ and disappearance of cristae structures of mitochondria. Data are presented as mean \pm s.d. ${ }^{\star} P<0.05,{ }^{\star \star} P<0.01,{ }^{\star \star \star} P<0.001$, versus control ( $t$-test).

to the level elicited by $25 \mathrm{nM}$ cccp (Supplementary Fig. S8b). More importantly, cccp had a larger effect on GSIS and glucose-induced ATP production in TBP-2-deficient ob/ob islets compared with $\mathrm{ob} / \mathrm{ob}$ islets (Fig. 6j,k). These results suggest that TBP-2-dependent regulation of GSIS is mainly achieved through mitochondrial uncoupling and metabolism.

These results suggest that TBP-2 does not affect mitochondrial biogenesis but enhances UCP-2 transcriptional activity through the PGC-1 $\alpha$-dependent pathway, and the induction of the TBP-2-UCP2 axis causes the defect of GSIS in ob/ob mice.

Mybbpla is a novel candidate binding protein for TBP-2. To obtain further insight on how TBP-2 regulates gene expression in $\beta$-cells, we purified the TBP- 2 protein complex using tosyl ( $\mathrm{p}$ toluene sulfonyl)-activated magnetic beads (Ts beads). His-taggedTBP-2 protein was conjugated to the beads and incubated with nuclear extract of INS-1 cells. After washing, the eluate fractions were subjected to SDS gel electrophoresis and silver staining (Fig. 7a). The specific bands on silver staining were subjected to proteolytic digestion and mass spectrometry. Mybbpla (p160), Mybbpla (p140), GCN and NonO/p54nrb homologue were identified (Fig. 7b and Supplementary Table S3). Intriguingly, Mybbp1a is reported to inhibit PGC-1 $\alpha$ function and transcription of PGC$1 \alpha$ target genes ${ }^{35}$. Therefore, we examined the interaction between TBP-2 and Mybbpla. We showed that Mybbpla is detected in elution samples from TBP-2 protein beads by anti-Mybbp1a antibody (Fig. 7c). To determine whether TBP-2 and Mybbpla interact directly in vivo, we performed co-immunoprecipitation using FLAG-HA-tagged Mybbpla and Myc-tagged TBP-2 expression vectors. Myc-tagged TBP-2 was co-immunoprecipitated with FLAG-HA-tagged Mybbp1a in HEK293 cells (Fig. 7d). Finally, we examined whether Mybbpla regulates UCP-2 transcriptional activity. Mybbp1a suppressed PGC-1 $\alpha$-dependent UCP-2 transcriptional activity and the suppression was reversed by TBP-2 
a

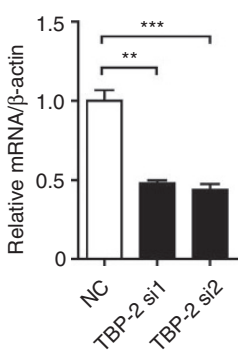

b

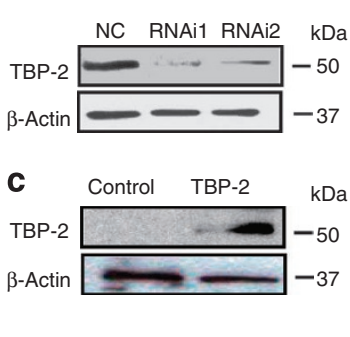

d

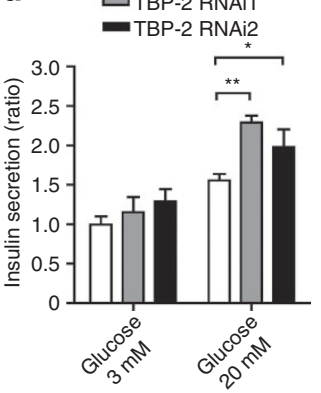

e

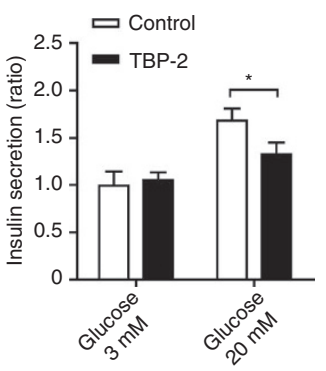

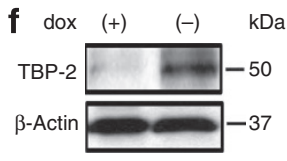

g

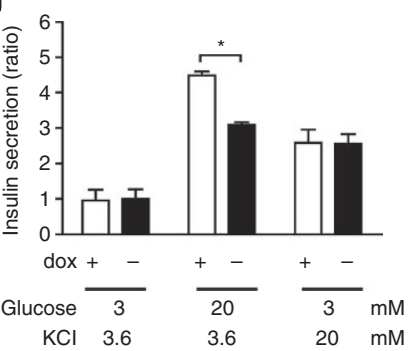

k

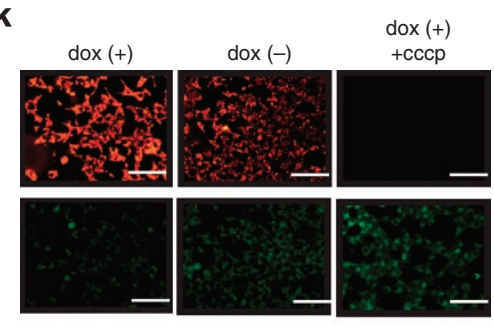

Mitochondria membrane potentia (jc-1)

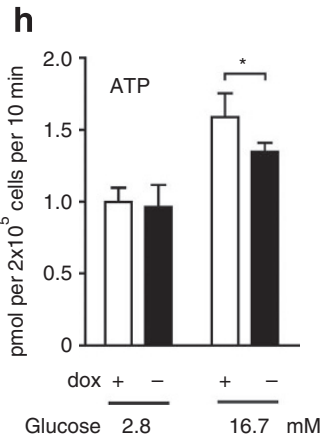

i
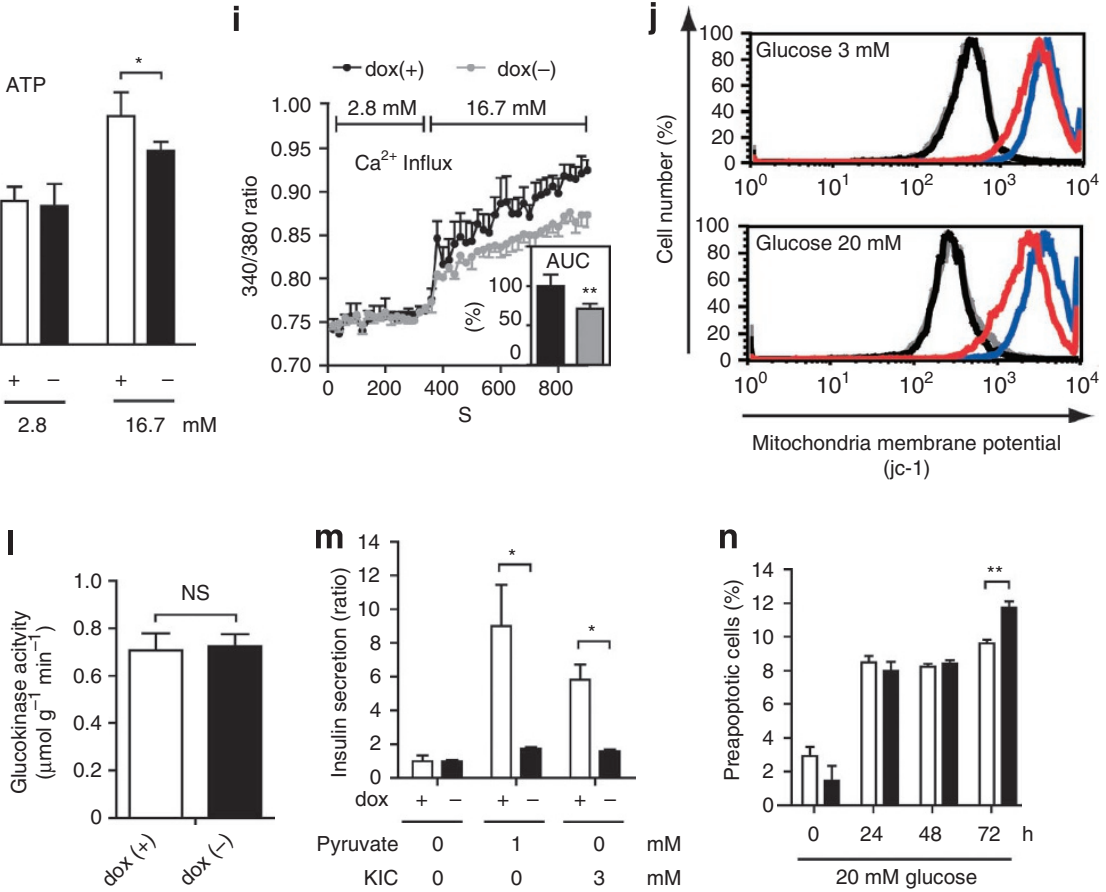

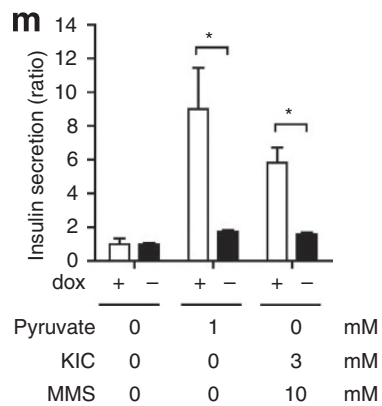

n

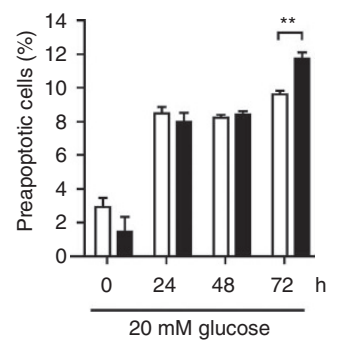

Figure 5 | TBP-2 suppresses glucose-induced mitochondrial energy production and insulin secretion in $\boldsymbol{\beta}$-cells. Transient TBP-2 knockdown by TBP2 siRNA (RNAi1 and RNAi2) and negative control siRNA (NC) in INS-1 cells. The expression of TBP-2 was determined by qRT-PCR (a) at 48 h after transfection and by immunoblot analysis (b) at $72 \mathrm{~h}$ after transfection. (c) Transient TBP-2 overexpression in INS-1 cells after $24 \mathrm{~h}$. The expression of TBP-2 was determined by immunoblot analyses. Augmentation or suppression of GSIS in TBP-2 knockdown (d) or TBP-2 overexpression (e) cells in RPMI cultured medium. Statistic insulin secretion assays were analysed in INS-1 cells. (f) Construction of the doxycycline (dox)-off-dependent TBP-2-overexpressed INS-1 cells. TBP-2 protein was suppressed by $1000 \mathrm{ng} \mathrm{ml}^{-1}$ dox and induced by dox removal. Cells were cultured with ( + , open bar) or without ( - , closed bar) dox for $24 \mathrm{~h}$. INS-1 cells were incubated at low ( 2.8 or $3 \mathrm{mM}$ ) or high ( 16.7 or 20 mM) glucose and experiments were performed. Suppression of high ( $20 \mathrm{mM})$ GSIS $(\mathbf{g})$, high $(16.7 \mathrm{mM})$ glucose-enhanced ATP contents (h) and intracellular Ca ${ }^{2+}$ influx (i) by dox-off TBP-2 overexpression, but not $\mathrm{KCl}$-induced insulin secretion $(\mathbf{g})$. The inset bar graph shows area under the curve levels (\%) of intracellular $\mathrm{Ca}^{2+}$ levels between 320 and 900 s (i). Decrease of mitochondrial membrane potentials (MMP) in dox-off TBP-2 overexpression in INS-1 cells. MMP of cultured cells in medium containing $3 \mathrm{mM}$ (upper panel) or $20 \mathrm{mM}$ (lower panel) glucose for $24 \mathrm{~h}$ was analysed by flow cytometry (j) or in cultured medium by fluorescence microscopy (k) using jc-1 reagent, scale bar is $100 \mu \mathrm{m}$. For disruption of MMP, $5 \mu \mathrm{M}$ carbonyl cyanide m-chlorophenlhydrazone (cccp) reagent was used. Flow cytometer, blue; dox (+), red; dox (-), black; dox (+) + cccp, grey; dox (-) + cccp. (I) Glucokinase (GK) activities in INS-1 cells, NS, nonsignificant. (m) Suppression of pyruvate (sodium pyruvate) or 2-ketoisohexanoic acid (KIC) and methylsaccinic acid (monomethyl succinate)stimulated insulin secretion by dox-off-dependent TBP-2 overexpression. (n) A flow cytometric analyses with Annexin V-fluorescein isothiocyanate and propidium iodide staining in the dox-off TBP-2-overexpressed INS-1 cells. Preapoptotic cells were calculated from triplicate samples (\%). Data are presented as mean \pm s.d. ${ }^{\star} P<0.05,{ }^{\star \star} P<0.01,{ }^{\star \star \star} P<0.001$, versus control $(t$-test $)$.

co-expression (Fig. 7e). These results provide a model that TBP-2 suppresses Mybbpla function possibly through protein-protein interaction, leading to the activation of PGC- $1 \alpha$-dependent UCP2 transcription (Fig. 7f).

\section{Discussion}

In this study, we demonstrated that disruption of TBP-2 expression augments both insulin sensitivity and secretion, resulting in the amelioration of glucose intolerance in a diabetic mice model where TBP-2 expression is increased. The mechanism by which TBP-2 is increased in several tissues and pancreatic islets of ob/ob mice is presently unknown. It is possible that high blood glucose or obeseinduced adipocytokines enhance TBP-2 expression, as TBP-2 is upregulated by several stimulations and stresses $^{36,37}$. Several reports have shown that TBP-2 expression is regulated by mitochondrial metabolism and glycolysis through the transcription factor 
a

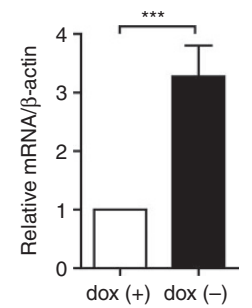

C

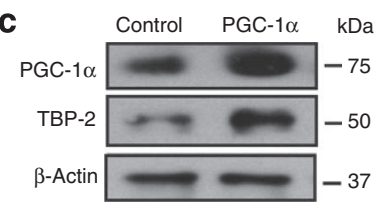

e

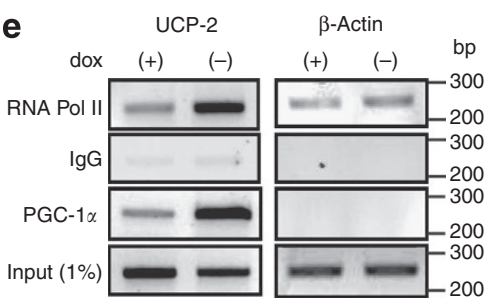

h
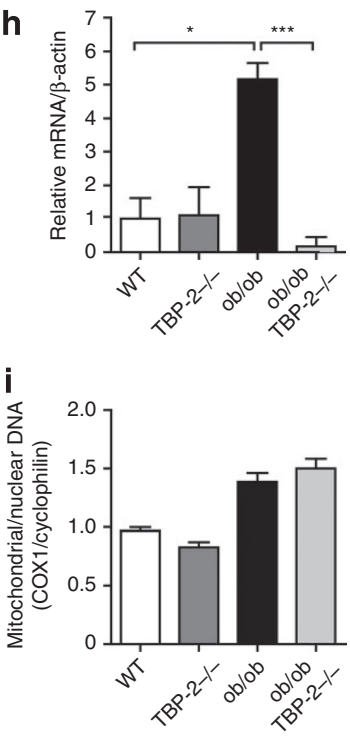
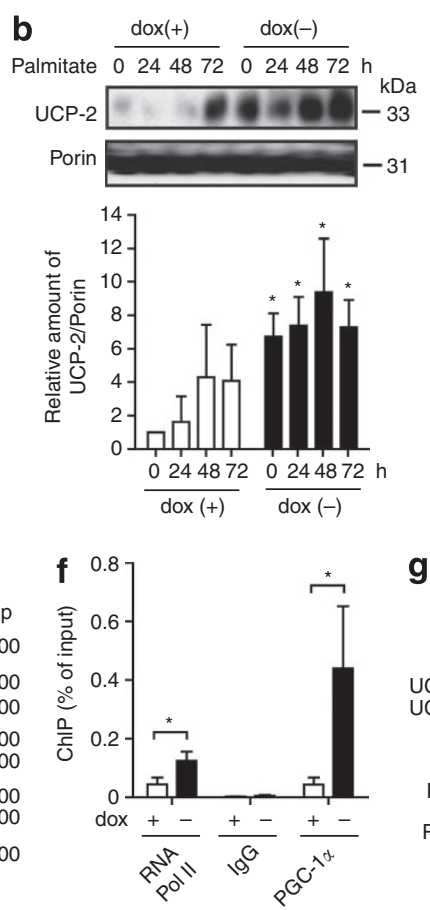

g
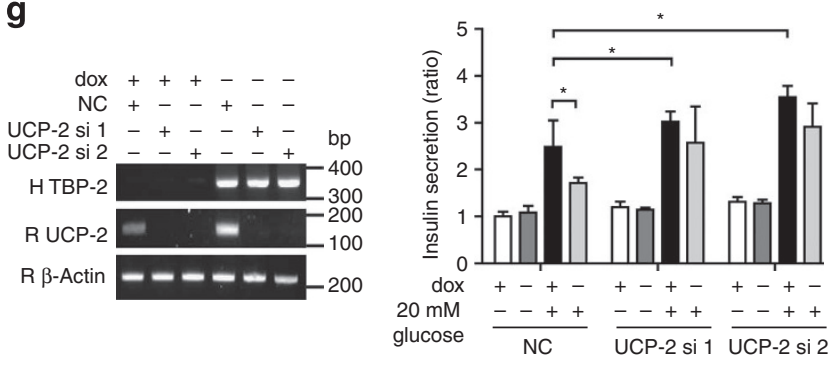

j
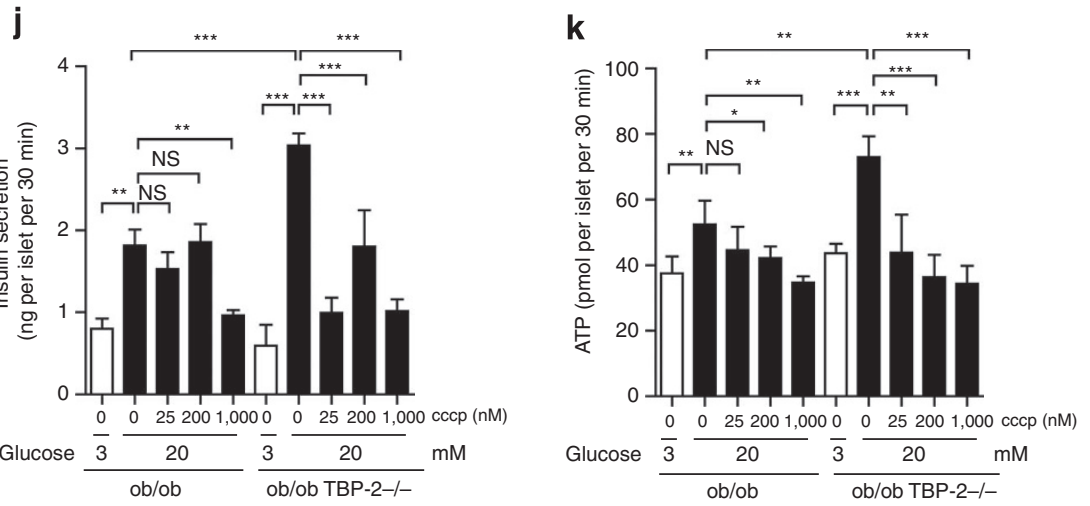

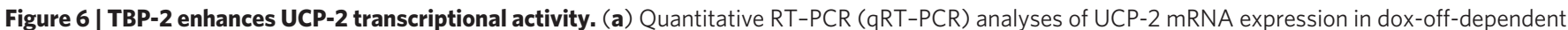
TBP-2-overexpressed INS-1 cells with or without dox. (b) Immuno blotting to determine UCP-2 expression in mitochondria in dox-off TBP-2 overexpression in INS-1 cells with or without palmitate $(300 \mu \mathrm{M})$ for the indicated time. Densitometric quantification of the UCP-2/Porin ratio in mitochondria of INS-1 cells is shown in a bar graph. (c) Immuno blotting analyses to detect expression of PGC-1 $\alpha$, TBP- 2 and $\beta$-actin in INS-1 cells, transiently transfected with PGC-1 $\alpha$ plasmid for 24h. (d) INS-1 cells were transfected with PGL4.10 UCP-2 -86 or PGL4.10-luciferase reporter plasmid and each expression plasmid for PGC-1 $\alpha$ and TBP-2, as indicated. Luciferase reporter activity was normalized by Renilla luciferase activity. (e) ChIP assay of PGC-1 $\alpha$ protein binding to endogenous UCP-2 promoter. Chromatin extracts from INS-1 cells in dox-off-dependent TBP-2-overexpressed INS-1 cells with or without dox were precipitated in the presence of control-mouse IgG, anti-RNA polymerase II (RNA pol II) or anti-PGC-1 $\alpha$ antibody. Primers for PCR are rat UCP-2 promoter region primers and rat $\beta$-actin primers. (f) qRT-PCR analyses for ChIP were performed. (g) Insulin secretion in dox-off-dependent TBP-2 overexpressing INS-1 cells with or without dox and knockdown of UCP-2 (si1 and si2). The left panel shows RT-PCR analysis of human TBP-2 expression (H TBP-2) to confirm the effect of dox, rat UCP-2 expression (R UCP-2) to confirm the knockdown effect, and rat $\beta$-actin (R $\beta$-actin). (h) qRT-PCR analyses of UCP-2 mRNA in isolated pancreatic islets of WT, TBP-2-/-, ob/ob and ob/ob-TBP-2-/- mice. (i) qRT-PCR was used to determine mitochondria content by measuring the expression of mitochondrial gene (COXI)/nuclear gene (cyclophilin) ratios. (j, k) Effect of cccp treatment for 30 min on insulin secretion

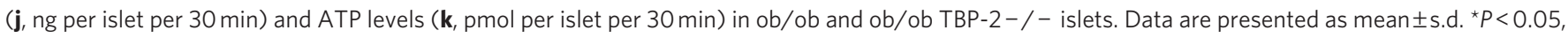
${ }^{\star \star} P<0.01,{ }^{\star \star \star} P<0.001$, versus control (t-test).

Mondo $\mathrm{A}^{38-41}$. These reports indicate that TBP-2 expression is tightly regulated in response to changes in energy status.

TBP-2 deficiency in ob/ob mice improved hyperglycaemia, glucose intolerance and insulin resistance without amelioration of obesity
(Fig. 1e-m). A previous study showed that HcB-19 mice crossed with ob/ob mice improved glucose tolerance ${ }^{21}$. Other studies showed that silencing of TBP-2 expression enhanced glucose uptake in adipocytes and human skeletal myocytes, whereas TBP-2 overexpression 
a

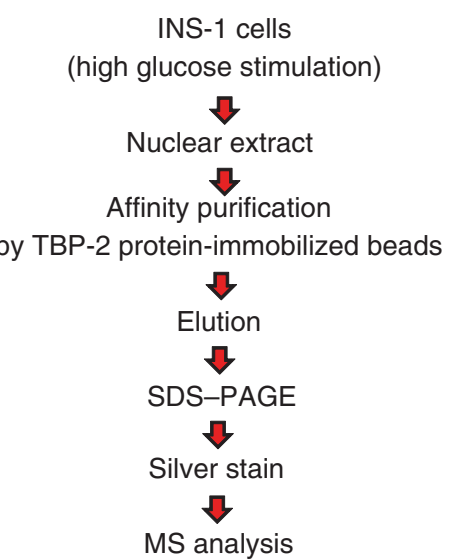

d

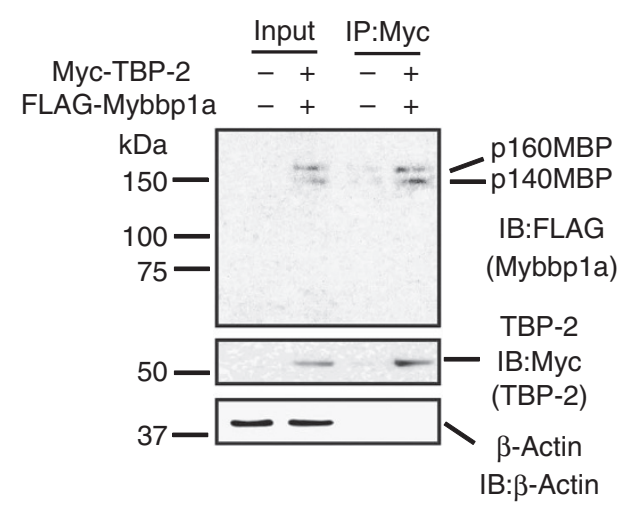

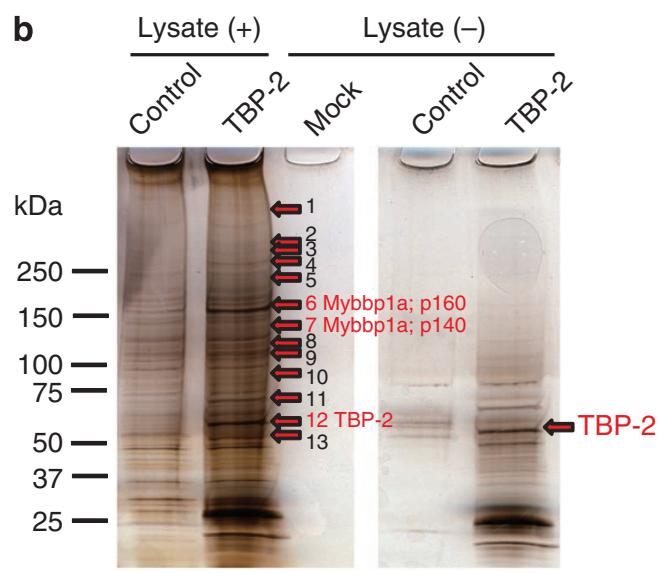

e

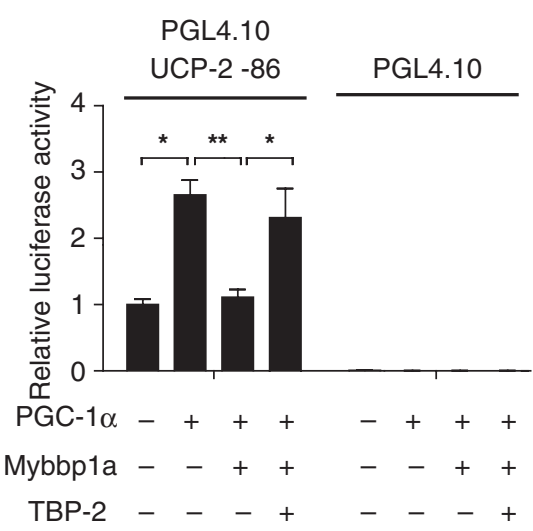

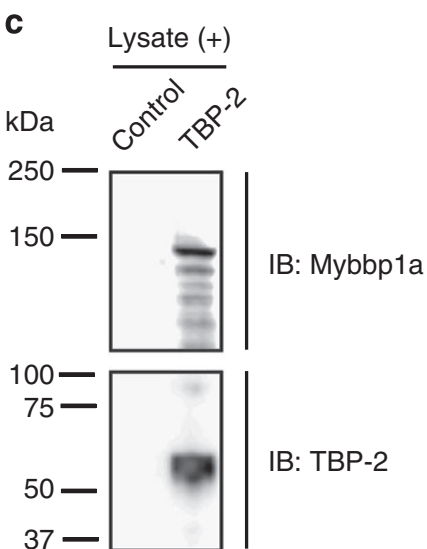

f

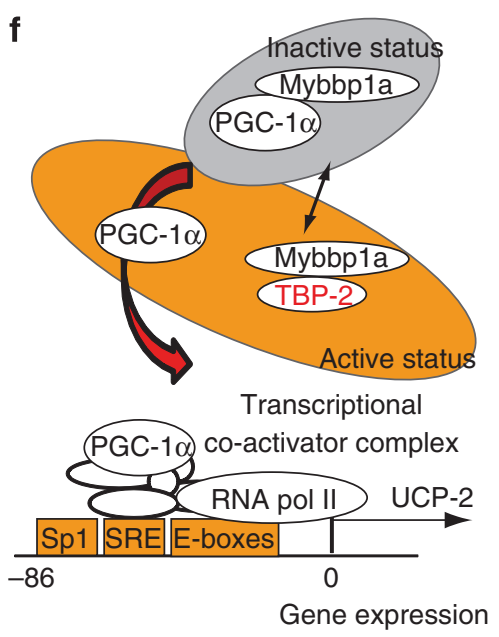

Figure 7 | Mybbp1a was identified as a novel candidate binding protein for TBP-2. (a) Purification scheme for the TBP-2 containing protein complex in $\beta$-cell nuclear extracts. TBP-2 binding proteins were purified from INS-1 nuclear extracts by using TBP-2 protein-immobilized (TBP-2) or control beads. (b) Identification of the TBP-2 complex. Silver staining was performed. Numbers indicate individual candidate proteins interacting with TBP-2. (c) Eluted proteins were analysed by immuno blotting (IB) for Mybbpla and TBP-2 antibody. (d) Co-immunoprecipitation analyses. Input (left, 5\% lysate) and anti-Myc immunoprecipitates (right, IP:Myc) from HEK293 cells transfected with pCMV-tag2A and pCMV-tag3B vector (-) or FLAG-HA-Mybbp1a and Myc-TBP-2 vector (+) were analysed by immunoblotting (IB) with antibodies to FLAG, Myc and $\beta$-actin. The positions for Mybbp1a (p160; p160MBP) and Mybbpla (p140; p140MBP) (upper), TBP-2 (middle) and $\beta$-actin (lower) are shown. (e) Luciferase activity of the UCP-2 -86 enhancer region. INS-1 cells were transfected with PGL4.10 UCP-2 -86 or PGL4.10-luciferase reporter plasmid and each expression plasmid for PGC-1 $\alpha$, Mybbp1a and TBP-2, as indicated. Luciferase reporter activity was normalized by Renilla luciferase activity. (f) A schematic model of TBP-2 function in $\beta$-cells. Mybbpla binds PGC-1 (inactive form) and inhibits UCP-2 transcriptional activity. Induced TBP-2 interacts with Mybbpla and releases PGC-1 $1 \alpha$ from Mybbpla, facilitating PGC-1 $\alpha$ recruitment on the UCP-2 promoter region. Data are presented as mean \pm s.d. ${ }^{\star} P<0.05,{ }^{\star \star} P<0.01$, versus control ( $t$-test).

inhibited glucose uptake ${ }^{19}$. Entire or muscle-specific TBP-2-/mice showed enhanced glucose uptake in the skeletal muscle and adipose with a high-fat $\operatorname{diet}^{23,42}$. The current study is consistent with these previous reports. The restoration of glucose tolerance in ob/ob.TBP-2-/ - mice could not be explained by changes in energy balance or hormonal level of adipocytokines, such as adiponectin, free fatty acids and MCP-1. Insulin resistance in skeletal muscle and liver is mainly caused by inactivation of insulin/Akt signalling ${ }^{1}$. We showed that TBP-2 deficiency in ob/ob mice improved Akt signalling in muscle but not liver (Fig. $2 \mathrm{k}-\mathrm{p}$ ). Moreover, IRS-1 gene and several insulin signalling genes were upregulated in skeletal muscle by TBP-2 deficiency both in WT and ob/ob mice (Fig. 3a and Supplementary Table S2). IRS-1 protein levels were downregulated in the skeletal muscle of $\mathrm{ob} / \mathrm{ob}$ mice compared with that of WT mice, while IRS-1 protein levels were also upregulated by TBP-2 deficiency in both WT and $\mathrm{ob} / \mathrm{ob}$ mice (Fig. $3 \mathrm{~b}$ ). As IRS-1 has a pivotal role in insulin sensitivity in muscle ${ }^{27}$, TBP-2 regulates insulin signalling possibly through the regulation of IRS-1 gene expression in muscle. Interestingly, TBP-2 deficiency did not change IRS-2 gene expression, which is known as a main regulator of liver insulin sensitivity ${ }^{43}$ in skeletal muscle (Fig. 3a). These results suggest that TBP-2 regulates IRS-1-related insulin sensitivity in skeletal muscle, but not IRS-2-related insulin sensitivity in liver. The molecular mechanism of how TBP-2 regulates the expression of IRS-1 and insulin signalling genes in skeletal muscle is now under investigation. We also found that gene expression of PPARs and their target genes, such as PPAR , PPAR $\alpha$, Acaca, Fabp3, Scd1 and $P d k 4$, are enhanced by TBP-2 deficiency in skeletal muscle (Supplementary Fig. S2), similar to previous reports in the liver and adipose tissue of TBP-2-/- mice ${ }^{16,42}$. As PPAR signalling augments insulin sensitivity ${ }^{44}$, it may also be involved in enhanced insulin sensitivity by TBP-2 deficiency.

The GSIS was significantly impaired in ob/ob islets, whereas insulin secretion from ob/ob.TBP-2-/ - islets was restored in vivo and ex vivo, suggesting that the ablation of TBP-2 in pancreatic islets of ob/ob mice augments GSIS. Our results indicate that upregulation of TBP-2 suppresses GSIS by reducing ATP production in pancreatic $\beta$-cells. Meanwhile, glycolytic activity was not changed by TBP-2 overexpression (Fig. 5l) in $\beta$-cell lines. Recently, several groups have 


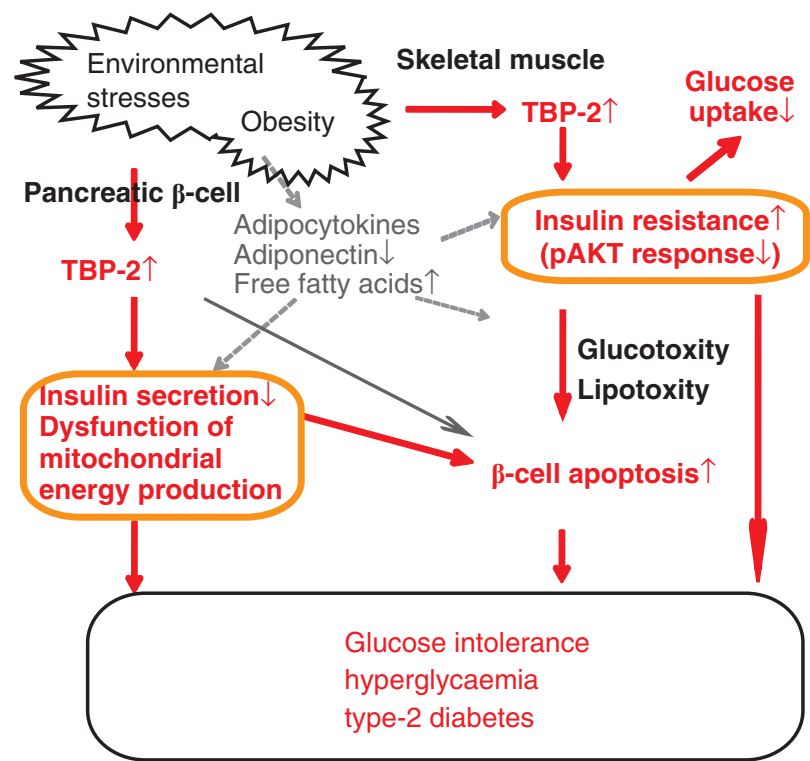

Figure 8 | A model for metabolic function of TBP-2 in diabetes. Role of TBP-2 in promoting obesity-induced type 2 diabetes. Environmental stresses including obesity cause upregulation of TBP-2. Sustained expression of TBP-2 may impair mitochondrial function and insulin secretion in $\beta$-cells and aggravate insulin resistance in skeletal muscle. Augmented expression of TBP-2 may also result in $\beta$-cell apoptosis. These changes lead to glucose intolerance and hyperglycaemia and obese-induced type 2 diabetes.

shown that TBP-2 regulates $\beta$-cell mass and $\beta$-cell apoptosis in $\mathrm{C} 3 \mathrm{H} /$ He background mice and INS-1 cell $\mathrm{s}^{21,22,45,46}$. Our results also support these previous studies. TBP- 2 deficiency suppressed $\beta$-cell apoptosis at age 36 weeks in C57BL/6J background mice (Supplementary Fig. S4b,c). In contrast, while $\beta$-cell apoptosis was not changed significantly between $\mathrm{ob} / \mathrm{ob}$ and ob/ob.TBP-2-/ - mice generated in C57BL/6J background mice at 10 weeks age (Supplementary Figs S3a,b and S4a,c), TBP-2 deficiency improved GSIS in ob/ob mice at age 10-14 weeks. Taken together, improvement of GSIS by TBP-2 depletion in vivo was attributable to functional amelioration of $\beta$ cells but not to an increase in $\beta$-cell mass, at least, in mice of this age. Moreover, impaired GSIS without reduction in $\beta$-cell mass preceded significant detection of apoptosis in islets in ob/ob mice, which supports the pathogenic importance of functional impairment of $\beta$-cells. Thus, TBP-2 seems to regulate not only $\beta$-cell apoptosis but also $\beta$-cell energy metabolism in the diabetic condition.

Impairment of GSIS in ob/ob mice was improved by TBP-2 deficiency. This phenotype resembles ob/ob mice lacking UCP-2, which is a negative regulator of GSIS ${ }^{24}$. We showed that TBP-2 deficiency cancelled upregulation of UCP-2 gene expression in ob/ob islets (Fig. 6h). Therefore, UCP-2 regulation by TBP-2 seems to be important in the development of the diabetic phenotype in ob/ob mice. UCP-2 knockdown recovered the TBP-2-dependent impairment in GSIS (Fig 6g). Furthermore, the mitochondrial uncoupling reagent cccp had a greater effect on GSIS and glucose-induced ATP production in TBP-2-deficient ob/ob islets compared with those in ob/ob islets (Fig. 6j,k). These results suggest that TBP-2-dependent regulation of GSIS is mainly due to mitochondrial uncoupling derived from UCP-2 expression.

The results from a ChIP assay indicated that TBP-2 regulates UCP-2 expression by facilitating PGC- $1 \alpha$ recruitment to the UCP2 promoter region. Furthermore, we identified Mybbpla as a novel binding protein of TBP-2. Mybbp1a is reported to inhibit PGC$1 \alpha$ function and transcription of PGC- $1 \alpha$ target genes through direct protein-protein interaction ${ }^{35}$. Indeed, Mybbpla overexpression suppressed PGC-1 $\alpha$-dependent UCP-2 transcriptional activity (Fig. 7e), and TBP-2 overexpression hampered the effect of Mybbpla on PGC-1 $\alpha$-dependent UCP-2 promoter activity in INS1 cells (Fig. 7e). These results suggest a model that TBP-2 regulates UCP-2 expression through Mybbpla and PGC-1 $\alpha$ pathway (Fig. $7 f)$. Recently, it has been reported that $\alpha$-arrestin family proteins are considered to act as adaptor protein for the E3-ubiquitin ligases in the yeast system ${ }^{47}$ and TBP-2 interacts with WW domain of HECT domain containing E3-ubiquitin ligases through the PPxY motif of TBP- $2^{12}$. These reports provide a hypothesis that TBP-2 negatively regulates Mybbp1a by protein degradation through E3ubiquitin ligases. This possibility should be further investigated.

In this study, we demonstrated that ablation of TBP-2 expression augments both insulin sensitivities by enhancing IRS-1/Akt signalling in skeletal muscle and GSIS by suppressing UCP-2 transcription and maintaining mitochondrial function in pancreatic $\beta$-cells, resulting in the amelioration of glucose intolerance and hyperglycaemia. The proposed mechanism for this effect is summarized in Figure 8 and Supplementary Figure S9. These findings raise the possibility that the inhibition of either TBP-2 activity or expression may be a novel therapeutic approach for type 2 diabetes.

\section{Methods}

Animal experiments. TBP-2-knockout mice were generated as described previously ${ }^{17}$. Mice were backcrossed for at least 11 generations with a C57B/6 genetic background. Animals were maintained in a specific pathogen-free animal facility on a 12-h light-dark cycle at an ambient temperature of $21^{\circ} \mathrm{C}$. They were given free access to water and food.

Age- and sex-matched mice were used for all animal experiments. All procedures involving animals were performed in accordance with protocols approved by the Animal Care and Research Advisory Committee of the Institute for Virus Research at Kyoto University.

Generation of TBP-2-deficient ob/ob mice. C57BL6 ob/ + were purchased from the Jackson Laboratory. To generate ob/ob·TBP-2-/ - mice, TBP-2-/ - mice were crossed with ob/ + mice creating compound heterozygotes, ob/OB.TBP- $2+1-$. In the second cross, compound heterozygotes were crossed to generate the following animals of which both males and females were collected and studied further: WT mice $(+/+$ at both ob and TBP-2 loci), ob/ob mice (ob/ob at the ob locus and $+/+$ at the TBP-2 locus), TBP- $2-/-$ mice $(+/+$ at the ob locus and $-/-$ at the TBP-2 locus) and ob/ob·TBP-2-I- mice (ob/ob at the ob locus and - / - at the TBP-2 locus). The ob allele was genotyped as previously described ${ }^{48}$.

Intraperitoneal glucose or ITTs. For the intraperitoneal (IP) glucose tolerance test, following an overnight fast, ob/ob and ob/ob·TBP-2 - / - mice were injected with $0.5 \mathrm{~g} \mathrm{~kg}^{-1}$ or $1 \mathrm{~g} \mathrm{~kg}^{-1}$ glucose. Blood glucose values were assessed before and at $15,30,60$ and 120 min after the IP administration of glucose using glucose PILOT. Serum insulin values were assessed before and at 5, 15, 30 and $45 \mathrm{~min}$ after the IP administration of glucose using an Insulin ELISA kit. For the IP ITTs, mice were fasted for $6 \mathrm{~h}$ and then injected with $1 \mathrm{U} \mathrm{kg}^{-1}$ insulin.

Cell culture and transfection. INS- 1 cells were cultured at $37^{\circ} \mathrm{C}$ with $5 \% \mathrm{CO}_{2}$ in air in RPMI1640 (Sigma-Aldrich), supplemented with 10\% (v/v) fetal bovine serum, $1 \%(\mathrm{v} / \mathrm{v})$ penicillin/streptomycin antibiotics, $10 \mathrm{mM}$ HEPES, $2 \mathrm{mM} \mathrm{L}$ glutamine, $1 \mathrm{mM}$ sodium pyruvate and $50 \mu \mathrm{M} \beta$-mercaptoethanol (RPMI for INS-1 medium). INS-1 cells were transfected with TBP-2 small interfering RNA (siRNA) or negative control siRNA (Qiagen) for $72 \mathrm{~h}$ or with pCMV-Tag2B-TBP-2 or control pCMV-Tag2B (Stratagene) plasmid for 24h and cultured with RPMI1640 for INS-1 medium.

Isolated pancreatic islet studies. Pancreatic islets were isolated from mice according to a method used for rats ${ }^{49}$.

Generation of INS-1 cells with inducible TBP-2 expression. Stable INS-1 cells, which carry the reverse tetracycline/doxycycline-dependent transactivator pTRE2 (pTet-Off, Clontech), were prepared. After selection with $500 \mu \mathrm{g} \mathrm{ml}^{-1} \mathrm{G} 418$, resistant colonies were isolated with limiting dilution methods in 96-well plates. One clonal line that exhibited very high tetracycline-off-inducible luciferase activity and undetectable basal luciferase activity was chosen and used for a second round of transfection with the TBP-2 expression plasmid (pTRE2 pur-TBP-2-FLAG). After selection with $500 \mathrm{ng} \mathrm{ml}^{-1}$ puromycin and doxycycline-off-induced TBP-2 expression, clones were isolated.

Insulin secretion assay using INS-1 cells. INS- 1 cells were transfected with TBP2 siRNA (Rn_Txnip_1 and 5) or UCP-2 siRNA (Rn_UCP-2_5 and 6) or negative control siRNA (purchased from Qiagen) for $72 \mathrm{~h}$, or with pCMV-Tag2A-TBP-2 or 
control pCMV-Tag2A (Stratagene) plasmid for $24 \mathrm{~h}$. Then, the cells were cultured in Krebs Ringer bicarbonate buffer (KRBB) (as mentioned below) or RPMI1640 for INS-1 medium with $2.8 \mathrm{mM}(5 \mathrm{mM})$ or $16.7 \mathrm{mM}(20 \mathrm{mM})$ glucose containing RPMI medium and the supernatant was collected $30 \mathrm{~min}$ after the addition of glucose. Insulin concentration was measured by an Insulin ELISA kit. Similar analyse were performed in Tet-TBP-2 INS-1 cells pretreated with or without doxycycline for 24 to $48 \mathrm{~h}$. One $\mathrm{mM}$ pyruvate (sodium pyruvate, Nacalai Tesque) or $3 \mathrm{mM}$ $\alpha$-ketoisocaprotate (2-ketoisohexanoic acid, Nacalai Tesque) and $10 \mathrm{mM}$ monomethyl succinate (methylsuccinic acid sodium salt, Sigma-Aldrich)-stimulated insulin secretion assays were performed in Tet-TBP-2 INS-1 cells.

Insulin secretion assay using primary mouse pancreatic islet. Insulin release from intact islets was monitored using batch incubation methods ${ }^{50}$. Isolated pan creatic islets were precultured at $37^{\circ} \mathrm{C}$ for $30 \mathrm{~min}$ with gentle swinging (50 times per min) in KRBB containing $129.4 \mathrm{mM} \mathrm{NaCl}, 3.7 \mathrm{mM} \mathrm{KCl}, 2.7 \mathrm{mM} \mathrm{CaCl}, 1.3 \mathrm{mM}$ $\mathrm{KH}_{2} \mathrm{PO}_{4}, 1.3 \mathrm{mM} \mathrm{MgSO}_{4}, 24.8 \mathrm{mM} \mathrm{NaHCO}_{3}$ (equilibrated with $5 \% \mathrm{CO}_{2}, 95 \% \mathrm{O}_{2}$ $\mathrm{pH} 7.4$ ), and $0.2 \%$ ( $\mathrm{vol} / \mathrm{vol}$ ) bovine serum albumin (fraction $\mathrm{V}$ ) with $2.8 \mathrm{mM}$ glucose. Next, the pancreatic islets were incubated for $30 \mathrm{~min}$ in KRBB buffer with glucose 2.8 or $16.7 \mathrm{mM}$ to determine insulin secretion levels. At the end of the incubation period, islets were pelleted by centrifugation, and aliquots of the buffer were sampled. The amount of immunoreactive insulin was determined by radioimmunoassay, using rat insulin as standard.

ATP contents assay. INS- 1 cells $\left(2.0 \times 10^{5}\right.$ cells per 24 -well plate $)$ or isolated pancreatic islets were precultured in $\mathrm{KRBB}$ buffer with $2.8 \mathrm{mM}$ glucose for $2 \mathrm{~h}$ or $30 \mathrm{~min}$, and were batch incubated for 10 or $30 \mathrm{~min}$ in KRBB with 2.8 or $16.7 \mathrm{mM}$ glucose, respectively. After immediate addition of $\mathrm{HClO}_{4}$, cells were sonicated in ice-cold water for $10 \mathrm{~min}$, and centrifuged. Part of the supernatant fraction was mixed with HEPES and $\mathrm{Na}_{2} \mathrm{CO}_{3}$ and the ATP content in the cells was determined by luminometer as previously described ${ }^{50}$.

Intracellular $\mathrm{Ca}^{2+}$ assay. INS-1 cells were precultured for $2 \mathrm{~h}$ in $\mathrm{KRBB}$ with $2.8 \mathrm{mM}$ glucose and then cells were loaded with $5 \mu \mathrm{M}$ Fura-PE3 AM in KRBB containing $2.8 \mathrm{mM}$ glucose and $0.2 \%$ bovine serum albumin at $37^{\circ} \mathrm{C}$ for $20 \mathrm{~min}$. Intracellular $\mathrm{Ca}^{2+}$ concentration was measured by the ratio of emission fluorescence of $510 \mathrm{~nm}$ by excitation at 340 and $380 \mathrm{~nm}$ as previously described ${ }^{50}$.

Measurement of mitochondrial membrane potentials. Briefly, INS- 1 cells were preincubated in KRBB with 3 and $20 \mathrm{mM}$ glucose or in cultured medium for $24 \mathrm{~h}$, and the cells were resuspended in $0.5 \mathrm{ml}$ of ice-cold PBS, then cultured with $10 \mathrm{nM}$ jc-1 (Sigma-Aldrich, J-4519) for $15 \mathrm{~min}$ in $5 \% \mathrm{CO}_{2}$ at $37^{\circ} \mathrm{C}$ with or without $5 \mu \mathrm{M}$ cccp, a protonophore that completely dissipated $\Delta \psi$, and was analysed by flow cytometry (FACSCanto II, BD Bioscience) or fluorescence microscopy (Biozero, Keyence). The greater the mitochondrial membrane potential, the more jc-1 aggregates form that have a red fluorescent emission signal, as opposed to the jc-1 monomer that fluorescences green. Data acquisition and analysis were performed using Cell Quest Software.

Luciferase reporter assays. INS- 1 cells were transiently transfected with pGL4.10 luc2 vectors containing UCP-2 -86 enhancer region (5'-GGCTCCGCCTCGT CACGCCACGCCCCGACCACGCCCTCTAGA-3') or pGL4.10 luc2 vectors, with the pCMV-PGC-1 $\alpha$, pCMV-Tag2A-TBP-2 and FLAG-HA-p160 MBP plasmids. FLAG-HA-p160 MBP was kindly provided by Dr Shunsuke Ishii. As a control, the total amount of vectors for transfection was adjusted by the amount of the pCMVTag2A vector. After $18 \mathrm{~h}$ of transfection, luciferase activity was quantified using the luciferase assay system (Promega). pRL-TK (Promega) was used to monitor Renilla luciferase gene expression as a control for the efficiency of transfection.

Cell culture of primary MEFs. Primary MEFs were derived from 13.5-day-old embryos from TBP- $2+/-$ mice, and then the MEFs were genotyped to obtain TBP- $2-/$ - and TBP- $2+/$ + MEFs. Cells were maintained in DMEM with $10 \%$ fetal calf serum, $1 \%$ penicillin and $0.5 \% \mathrm{~L}$-glutamine. TBP- 2 mRNA expression was confirmed by semiquantitative RT-PCR analysis. Primer sequences are listed in Supplementary Table S4.

Quantitative (semiquantitative) RT-PCR analysis. Total RNA was extracted from INS-1 cells or handpicked freshly isolated islets using TRIzol reagent (Invitrogen). Reverse transcription was performed with SuperScript III (Invitrogen) or PrimeScript RT (TAKARA). Real-time RT-PCR was performed using SYBR Premix Ex Tag II(TAKARA). The internal control used was $\beta$-actin. PCR analyses were carried out using the oligonucleotide primers listed in Supplementary Table S4.

Chromatin immunoprecipitation. Chromatin was prepared from Tet-TBP-2 INS 1 cells treated with or without doxycycline. Briefly, $5 \times 10^{6}$ cells were crosslinked with $1 \%$ formaldehyde for $10 \mathrm{~min}$, followed by the addition of glycine at $125 \mathrm{mM}$. Chromatin was sheared by enzymes (CHIP IT Express Kit, Active Motif). Chromatin was immunoprecipitated with $2 \mu \mathrm{g}$ anti-RNA polymerase II (Active Motif), control-mouse immunoglobulin G (Active Motif) or anti-PGC- $1 \alpha$ antibodies (Santa Cruz). GATCTGAGACAGGGAGACTCTAGG and GGAGAATACACA GGAGAACACAGG primers were used to amplify the UCP-2 SP1, SRE, E-boxes region. Rat $\beta$-actin enhancer primers (Active Motif) were used as control. PCR was carried out with one cycle at $95^{\circ} \mathrm{C}$ for $2 \mathrm{~min} ; 36$ cycles at $94^{\circ} \mathrm{C}$ for $10 \mathrm{~s}, 60^{\circ} \mathrm{C}$ for $30 \mathrm{~s}, 68^{\circ} \mathrm{C}$ for $1 \mathrm{~min}$; and one cycle at $68^{\circ} \mathrm{C}$ for $5 \mathrm{~min}$.

Co-immunoprecipitation. To investigate interactions between TBP-2 and Mybbpla in vivo, Myc-TBP-2 and FLAG-HA-Mybbpla or pCMV-tag3B and pCMV-tag2A (as control) were co-expressed in HEK293 cells. Cells were lysed in lysis buffer (CellLytic M Cell Lysis Reagent, Sigma-Aldrich), and insoluble materials were precipitated by centrifugation at $15,000 \times g$ for $15 \mathrm{~min}$. The resulting supernatants were incubated with anti-Myc agarose beads (MBL), and bound material was eluted with Myc-peptide $\left(500 \mu \mathrm{g} \mathrm{ml}^{-1}, \mathrm{MBL}\right)$. Protein-protein interaction was assessed by immunoblotting using anti-FLAG antibody (Sigma-Aldrich) or anti-Myc antibody (Sigma-Aldrich).

Statistical method. Results were expressed as the mean \pm s.d. Statistical comparisons were made using Student's $t$-test. A statistically significant difference was defined as ${ }^{\star} P<0.05,{ }^{* *} P<0.01,{ }^{* *} P<0.001$.

\section{References}

1. Biddinger, S. B. \& Kahn, C. R. From mice to men: insights into the insulin resistance syndromes. Annu. Rev. Physiol. 68, 123-158 (2006).

2. Guilherme, A., Virbasius, J. V., Puri, V. \& Czech, M. P. Adipocyte dysfunctions linking obesity to insulin resistance and type 2 diabetes. Nat. Rev. Mol. Cell Biol. 9, 367-377 (2008).

3. Pratley, R. E. \& Weyer, C. The role of impaired early insulin secretion in the pathogenesis of Type II diabetes mellitus. Diabetologia 44, 929-945 (2001).

4. Anello, M. et al. Functional and morphological alterations of mitochondria in pancreatic beta cells from type 2 diabetic patients. Diabetologia 48, 282-289 (2005).

5. Maechler, P. \& Wollheim, C. B. Mitochondrial function in normal and diabetic beta-cells. Nature 414, 807-812 (2001).

6. Bodnar, J. S. et al. Positional cloning of the combined hyperlipidemia gene Hyplip1. Nat. Genet. 30, 110-116 (2002).

7. Chen, K. S. \& DeLuca, H. F. Isolation and characterization of a novel cDNA from HL-60 cells treated with 1,25-dihydroxyvitamin D-3. Biochim. Biophys. Acta. 1219, 26-32 (1994).

8. Nishiyama, A. et al. Identification of thioredoxin-binding protein-2/vitamin $\mathrm{D}(3)$ up-regulated protein 1 as a negative regulator of thioredoxin function and expression. J. Biol. Chem. 274, 21645-21650 (1999).

9. Nishinaka, Y. et al. Importin alpha1 (Rch1) mediates nuclear translocation of thioredoxin-binding protein-2/vitamin $\mathrm{D}(3)$-up-regulated protein 1. J. Biol. Chem. 279, 37559-37565 (2004).

10. Oka, S. et al. Thioredoxin-binding protein-2-like inducible membrane protein is a novel vitamin D3 and peroxisome proliferator-activated receptor (PPAR)gamma ligand target protein that regulates PPARgamma signaling. Endocrinology 147, 733-743 (2006).

11. Patwari, P. et al. Thioredoxin-independent regulation of metabolism by the alpha-arrestin proteins. J. Biol. Chem. 284, 24996-5003 (2009).

12. Zhang, P. et al. The ubiquitin ligase itch regulates apoptosis by targeting thioredoxin-interacting protein for ubiquitin-dependent degradation. J. Biol. Chem. 285, 8869-79 (2010).

13. Zhou, R., Tardivel, A., Thorens, B., Choi, I. \& Tschopp, J. Thioredoxininteracting protein links oxidative stress to inflammasome activation. Nat. Immunol. 11, 136-140 (2010).

14. Nishinaka, Y. et al. Loss of thioredoxin-binding protein-2/vitamin D3 up regulated protein 1 in human T-cell leukemia virus type I-dependent T-cell transformation: implications for adult T-cell leukemia leukemogenesis. Cancer Res. 64, 1287-1292 (2004).

15. Lee, K. N. et al. VDUP1 is required for the development of natural killer cells Immunity 22, 195-208 (2005)

16. Oka, S. et al. Thioredoxin binding protein-2/thioredoxin-interacting protein is a critical regulator of insulin secretion and peroxisome proliferator-activated receptor function. Endocrinology 150, 1225-1234 (2009).

17. Oka, S. et al. Impaired fatty acid utilization in thioredoxin binding protein-2 (TBP-2)-deficient mice: a unique animal model of Reye syndrome. FASEB J. 20 , 121-123 (2006)

18. Hui, T. Y. et al. Mice lacking thioredoxin-interacting protein provide evidence linking cellular redox state to appropriate response to nutritional signals. J. Biol. Chem. 279, 24387-24393 (2004).

19. Parikh, H. et al. TXNIP regulates peripheral glucose metabolism in humans. PLoS Med. 4, e158 (2007).

20. Chutkow, W. A., Patwari, P., Yoshioka, J. \& Lee, R. T. Thioredoxin-interacting protein (Txnip) is a critical regulator of hepatic glucose production. J. Biol. Chem. 283, 2397-2406 (2008).

21. Chen, J. et al. Thioredoxin-interacting protein deficiency induces Akt/Bcl-xL signaling and pancreatic beta-cell mass and protects against diabetes. FASEB J. 22, 3581-3594 (2008)

22. Chen, J., Saxena, G., Mungrue, I. N., Lusis, A. J. \& Shalev, A. Thioredoxininteracting protein: a critical link between glucose toxicity and beta-cell apoptosis. Diabetes 57, 938-944 (2008). 
23. Hui, S. T. et al. Txnip balances metabolic and growth signaling via PTEN disulfide reduction. Proc. Natl Acad. Sci. USA 105, 3921-3926 (2008).

24. Zhang, C. Y. et al. Uncoupling protein-2 negatively regulates insulin secretion and is a major link between obesity, beta cell dysfunction, and type 2 diabetes. Cell 105, 745-755 (2001).

25. Rosen, E. D. \& Spiegelman, B. M. Adipocytes as regulators of energy balance and glucose homeostasis. Nature 444, 847-853 (2006).

26. Sreekumar, R., Halvatsiotis, P., Schimke, J. C. \& Nair, K. S. Gene expression profile in skeletal muscle of type 2 diabetes and the effect of insulin treatment. Diabetes 51, 1913-1920 (2002).

27. Tamemoto, H. et al. Insulin resistance and growth retardation in mice lacking insulin receptor substrate-1. Nature 372, 182-186 (1994).

28. Muoio, D. M. \& Newgard, C. B. Mechanisms of disease: molecular and metabolic mechanisms of insulin resistance and beta-cell failure in type 2 diabetes. Nat. Rev. Mol. Cell Biol. 9, 193-205 (2008)

29. Hackenbrock, C. R. Ultrastructural bases for metabolically linked mechanical activity in mitochondria. I. Reversible ultrastructural changes with change in metabolic steady state in isolated liver mitochondria. J. Cell Biol. 30, 269-297 (1966).

30. Bonnard, C. et al. Mitochondrial dysfunction results from oxidative stress in the skeletal muscle of diet-induced insulin-resistant mice. J. Clin. Invest. 118, 789-800 (2008).

31. Meglasson, M. D. \& Matschinsky, F. M. Pancreatic islet glucose metabolism and regulation of insulin secretion. Diabetes Metab. Rev. 2, 163-214 (1986).

32. MacDonald, M. J. Synergistic potent insulin release by combinations of weak secretagogues in pancreatic islets and INS-1 cells. J. Biol. Chem. 282, 6043-6052 (2007).

33. Oberkofler, H., Klein, K., Felder, T. K., Krempler, F. \& Patsch, W. Role of peroxisome proliferator-activated receptor-gamma coactivator-1alpha in the transcriptional regulation of the human uncoupling protein 2 gene in INS-1E cells. Endocrinology 147, 966-976 (2006).

34. Medvedev, A. V. et al. Regulation of the uncoupling protein-2 gene in INS-1 beta-cells by oleic acid. J. Biol. Chem. 277, 42639-42644 (2002).

35. Fan, M. et al. Suppression of mitochondrial respiration through recruitment of p160 myb binding protein to PGC-1alpha: modulation by p38 MAPK. Genes Dev. 18, 278-289 (2004).

36. Ahsan, M. K., Nakamura, H., Masutani, H. \& Yodoi, J. Thioredoxin and thioredoxin-binding protein-2 in cancer and metabolic syndrome. Free Radic. Biol. Med. 43, 861-868 (2007).

37. Yoshihara, E., Chen, Z., Matsuo, Y., Masutani, H. \& Yodoi, J. Thiol redox transitions by thioredoxin and thioredoxin-binding protein-2 in cell signaling. Methods Enzymol. 474, 67-82 (2010).

38. Stoltzman, C. A. et al. Glucose sensing by MondoA:Mlx complexes: a role for hexokinases and direct regulation of thioredoxin-interacting protein expression. Proc. Natl Acad. Sci. USA 105, 6912-6917 (2008).

39. Peterson, C. W., Stoltzman, C. A., Sighinolfi, M. P., Han, K. S. \& Ayer, D. E. Glucose controls nuclear accumulation, promoter binding, and transcriptional activity of the MondoA-Mlx heterodimer. Mol. Cell Biol. 30, 2887-2895 (2010)

40. Kaadige, M. R., Looper, R. E., Kamalanaadhan, S. \& Ayer, D. E. Glutaminedependent anapleurosis dictates glucose uptake and cell growth by regulating MondoA transcriptional activity. Proc. Natl Acad. Sci. USA 106, 14878-14883 (2009).

41. Chen, J. L. et al. Lactic Acidosis Triggers Starvation Response with Paradoxical Induction of TXNIP through MondoA. PLoS Genet. 6, e1001093 (2010).

42. Chutkow, W. A. et al. Deletion of the alpha-arrestin protein Txnip in mice promotes adiposity and adipogenesis while preserving insulin sensitivity. Diabetes 59, 1424-1434 (2010)
43. Sesti, G. et al. Defects of the insulin receptor substrate (IRS) system in human metabolic disorders. FASEB J. 15, 2099-2111 (2001).

44. Ferre, P. The biology of peroxisome proliferator-activated receptors: relationship with lipid metabolism and insulin sensitivity. Diabetes $\mathbf{5 3}$ (Suppl 1), S43-50 (2004).

45. Shaked, M. et al. Insulin counteracts glucotoxic effects by suppressing thioredoxin-interacting protein production in INS-1E beta cells and in Psammomys obesus pancreatic islets. Diabetologia 52, 636-644 (2009).

46. Masson, E. et al. High beta-cell mass prevents streptozotocin-induced diabetes in thioredoxin-interacting protein-deficient mice. Am. J. Physiol. Endocrinol. Metab. 296, E1251-1261 (2009).

47. Lin, C. H., MacGurn, J. A., Chu, T., Stefan, C. J. \& Emr, S. D. Arrestin-related ubiquitin-ligase adaptors regulate endocytosis and protein turnover at the cell surface. Cell 135, 714-725 (2008).

48. Hirasawa, T., Ohara, T. \& Makino, S. Genetic typing of the mouse ob mutation by PCR and restriction enzyme analysis. Exp. Anim. 46, 75-78 (1997).

49. Sutton, R., Peters, M., McShane, P., Gray, D. W. \& Morris, P. J. Isolation of rat pancreatic islets by ductal injection of collagenase. Transplantation 42, 689-691 (1986)

50. Fujimoto, S. et al. The novel insulinotropic mechanism of pimobendan: Direct enhancement of the exocytotic process of insulin secretory granules by increased Ca2+ sensitivity in beta-cells. Endocrinology 139, 1133-1140 (1998).

\section{Acknowledgments}

We thank Dr Akira Kakizuka for kindly providing PGC-1 $\alpha$ vector and helpful discussion. We also thank Dr Shunsuke Ishii for kindly providing Mybbpla vector, Tamagawa Seiki Co. Ltd for providing tosyl-activated magnetic beads, Ms Ryoko Otsuki, Suzuyo Furukawa for technical assistance, Drs Eri Mukai and Yuichi Nishi for technical support and Drs Masahiko Sugita and Fuyuki Ishikawa for discussion. This work was supported by a Grant-in-Aid for Scientific Research from the Ministry of Education, Culture, Sports, Science, and Technology of Japan. This work was also supported in part by the Program for the Promotion of Fundamental Studies in Health Sciences of the National Institute of Biomedical Innovation (NIBIO). E.Y. was supported by a Research Fellowship from the Japan Society for the Promotion of Science for Young Scientists.

\section{Author contributions}

E.Y. designed and performed the experiments and wrote the manuscript with the help of S.F., N.I., J.Y. and H.M. E.Y., S.F., N.I and H.M. analysed the data. K.O. performed mass spectrometry analysis. S.M. prepared protein-immobilized beads. J.Y. directed the project as the principal investigator. H.M. supervised the study. All authors discussed the results and commented on the manuscript.

\section{Additional information}

Supplementary Information accompanies this paper on http://www.nature.com/ naturecommunications

Competing financial interests: The authors declare no competing financial interests. Reprints and permission information is available online at http://npg.nature.com/ reprintsandpermissions/

How to cite this article: Yoshihara, E. et al. Disruption of TBP-2 ameliorates insulin sensitivity and secretion without affecting obesity. Nat. Commun. 1:127 doi: 10.1038/ncomms1127 (2010)

License: This work is licensed under a Creative Commons Attribution-NonCommercialShare Alike 3.0 Unported License. To view a copy of this license, visit http:// creativecommons.org/licenses/by-nc-sa/3.0/ 